\title{
ESPACIO Y TIEMPO EN LA VIDA HUMANA Y SU EXPERIENCIA EN EL ARTE. UN ESTUDIO EN TORNO AL INTERCAMBIO INTELECTUAL ENTRE MARTIN HEIDEGGER Y EDUARDO CHILLIDA*
}

\author{
ANA MARÍA RABE \\ Universidad de Antioquia
}

\begin{abstract}
RESUMEN: Martin Heidegger y Eduardo Chillida mantuvieron un rico y fértil intercambio intelectual en los años 1968 y 1969, cuando estaban preparando el libro de bibliófilo Die Kunst und der Raum («El arte y el espacio") que contendría un texto sobre el arte y el espacio, escrito por Heidegger, y siete lito-collages, además de una litografía creadas por Chillida. El artículo trata la similitud que hay entre las concepciones de espacio y tiempo del pensador alemán y del escultor vasco-español. Ambos conciben el espacio en relación con el tiempo como algo dinámico, inseparable de la vida y experiencia humana, que no está simplemente "dado», sino que hay que buscar y realizar. El punto de partida de este artículo es una circunstancia que no ha sido investigada hasta el momento: Heidegger leyó y discutió con Chillida las reflexiones sobre el espacio que éste había escrito y que le había mandado a principios de 1969 a petición suya. Al final del artículo se publican por primera vez las reflexiones de Chillida, que Heidegger usó en una traducción alemana cuando estaba preparando su texto sobre «El arte y el espacio", así como una selección más grande de reflexiones de Chillida, que el artista pudo haber mandado al filósofo, y finalmente también una página de los apuntes que Heidegger hizo sobre Chillida.
\end{abstract}

PALABRAS CLAVE: espacio; tiempo; arte; lugar; vacío; experiencia; límite.

\section{Space and Time in Human Life and its Experience in Art. A Study on the Intellectual Exchange between Martin Heidegger and Eduardo Chillida}

ABSTRACT: Martin Heidegger and Eduardo Chillida held a rich and fertile intellectual exchange in 1968 and 1969, by the time they were preparing the artists' book Die Kunst und der Raum ("The Art and the Space»), which was to contain a text on art and space, written by Heidegger, as well as seven litho-collages and one lithography created by Chillida. The article deals with the similarity that

* Este artículo presenta resultados del proyecto de investigación «Espacio y tiempo en la vida humana y su experiencia en el arte. Resultados de un diálogo entre el filósofo Martin Heidegger y el escultor Eduardo Chillida», que la autora ha llevado a cabo como investigadora principal en el marco de la convocatoria «Fondo de apoyo al primer proyecto en la Universidad de Antioquia». Agradezco al Museo Chillida Leku, a la Fundación Eduardo Chillida - Pilar Belzunce y a la familia Chillida por el permiso de realizar extensas búsquedas e investigaciones en los archivos, las bibliotecas y colecciones de Chillida Leku y de la familia. Agradezco de todo corazón su ayuda durante todo el proceso de realización de mi proyecto de investigación y la autorización de publicar los manuscritos de E. Chillida. Doy las gracias a Arnulf Heidegger por su ayuda, el amable permiso y la autorización para la publicación de los manuscritos de M. Heidegger. También agradezco el interés, la amabilidad y gran ayuda de Almuth Heidegger en la transcripción de los apuntes de M. Heidegger. Finalmente extiendo mi gratitud a Ricardo Pinilla, que me ha acompañado y colaborado con constante interés en las diferentes etapas del proceso, por su valiosa ayuda y los fértiles encuentros e intercambios que he tenido con él. 
exists between the German philosopher's and the Spanish-Basque sculptor's conception of space and time. Both understand space in connection with time as something dynamic, inseparable from life and human experience, which is not simply "given», but has to be looked for and realized. Starting point of this article is a circumstance that has not been investigated up to now: Heidegger read and discussed with Chillida the reflections on space that the latter had written and sent to him in the early 1969 at his request. At the end of the article, Chillida's reflections used by Heidegger in a German translation, when he was preparing his text on «The Art and the Space», will be published for the first time, as well as a bigger selection of Chillida's reflections, which the artist could have sent to the philosopher, and finally a page of the notes, which Heidegger took on Chillida.

KEY WORDS: space; time; art; place; void; experience; limit.

El intercambio intelectual entre Chillida y Heidegger en la fase preparatoria DEL LIBRO DE BIBLIÓFILO EL ARTE Y EL ESPACIO

El filósofo alemán Martin Heidegger y el escultor vasco-español Eduardo Chillida se conocieron el 23 de noviembre de 1968 en la inauguración de una exposición en la Galerie im Erker en la ciudad suiza de St. Gallen. Se mostraban el libro de bibliófilo Meditation in Kastilien, que Chillida había creado junto con el poeta Max Hölzer, y otras obras gráficas de Chillida, además de siete esculturas y relieves de hierro y alabastro que el escultor donostiarra había creado entre 1953 y $1968^{1}$. Durante la visita conjunta de la exposición, el escultor y el filósofo mantuvieron una larga conversación. Según recuerda Chillida unos años después, un alumno de Heidegger le traducía a éste todo lo que el artista contaba. Chillida asegura que intentó comunicarse con el filósofo en inglés y en francés antes de usar el español. Heidegger parecía entender, según el artista, todos estos idiomas, pero prefería «expresarse en la lengua que

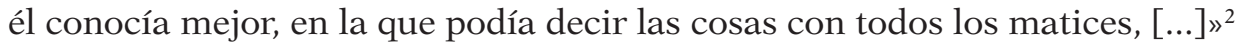

1 No existe —o bien no se conserva- ningún catálogo de esta exposición. La única información sobre la obra expuesta la he encontrado en la revista Das Werk: Architektur und Kunst $=$ L'oeuvre: architecture et art, vol. 56, 1969, p. 145.

2 Ugalde, M. DE, Hablando con Chillida. Vida y Obra (Período 1924-1975), Donostia - San Sebastián, Txertoa, 2007, p. 97. En algunas entrevistas y anotaciones personales de Chillida, el artista hace referencia al intercambio intelectual que hubo entre él y Heidegger desde que se conocieron (en noviembre de 1968) hasta que se publicó la obra conjunta (en octubre de 1969). La entrevista con Martín de Ugalde, en la que aparecen los recuerdos citados de Chillida y que se realiza pocos años después de terminar y publicarse el libro de bibliófilo Die Kunst und der Raum, representa el testimonio de Chillida que más información y detalles aporta sobre los encuentros, la colaboración y el intercambio entre el filósofo y el artista. Pero ya en esta conversación con Ugalde - y más todavía en posteriores entrevistas y apuntes-, Chillida confunde los lugares y momentos de los encuentros, las exposiciones y los acontecimientos, lo cual distorsiona la visión del orden cronológico de los sucesos. Por otro lado llama la atención que Chillida repita en diferentes momentos de su vida que Heidegger no sólo estaba muy interesado en sus ideas, sino que le pidió incluso que le mandara todo lo que hubiera escrito sobre el espacio. Chillida resalta que Heidegger leyó sus reflexiones con mucho interés y que hubo varios encuentros e intercambios entre los dos por aquella época. Una parte del proyecto de investigación, que la autora de este artículo ha realizado, consistía 
El primer encuentro entre Chillida y Heidegger no debe entenderse como una simple conversación sobre la obra expuesta del artista. El filósofo no sólo se interesó por la obra gráfica y escultórica ${ }^{3}$, sino que tenía, además, un especial interés en lo que el artista pensaba sobre el problema de espacio y tiempo. Escuchando al escultor, reconocería inmediatamente las coincidencias con su propio pensamiento. Estas afinidades intelectuales le convencerían de que Chillida sería el artista idóneo para ocuparse de la parte artística de un libro de bibliófilo sobre la relación entre arte y espacio, que estaba planeando hacer. Resulta asombroso que Heidegger tuviera en mente realizar una obra de este tipo en colaboración con un artista. Quería hacer un libro que, además de contener un texto, tuviera un formato artístico y contara con obras gráficas. En realidad, la idea para esta obra se la habían dado los galeristas Franz Larese y

en buscar documentos históricos que aclarasen con exactitud cuándo y dónde se realizó el primer encuentro entre Chillida y Heidegger, qué pasó tras ese encuentro, en qué momento le propuso Heidegger a Chillida hacer el libro de artista, cómo se desarrolló a continuación la colaboración, cuándo y cómo se desarrolló el proceso de redacción del texto de Heidegger, de qué manera pudieron haber entrado en juego en ese proceso las ideas y preguntas de Chillida y los encuentros con él, qué exposiciones de Chillida - en qué momento y lugarpodían haber visitado juntos, etc. Sólo tras el descubrimiento de documentos históricos que fundamentan y fortalecen la hipótesis de un diálogo intenso y la importancia que tuvieron las ideas de Chillida para Heidegger pude corregir los errores y las incongruencias que habían surgido por los fallos de la memoria de Chillida, los cuales — por pequeños que fuerandificultaban y confundían la comprensión de la colaboración entre los dos.

3 En la recopilación de textos de Chillida recogida en el libro Escritos se reproducen unos recuerdos de Chillida en los que el artista hace alusión a las múltiples preguntas que Heidegger le hacía al recorrer la exposición. Tal y como hemos dicho en la anterior nota, Chillida confunde también en esta ocasión - pero de manera diferente que en la entrevista con Ugalde- las fechas, los lugares y la cronología de los acontecimientos. Entre los errores se encuentra la confusión de la exposición en St. Gallen en noviembre de 1968, donde se conocieron Heidegger y Chillida, con la retrospectiva de Chillida en la Kunsthalle en Zúrich en la primavera del '69, donde el filósofo y el artista se volverían a ver. Chillida recuerda lo siguiente: «Esa especie de síntesis de un doble discurso intuición-razón es más comprensible para los ingenieros, pero no para todos. Por ejemplo, tengo un amigo americano, Holton, que vivió en Cambridge y era físico. Nos hicimos muy amigos porque encontrábamos unos terrenos comunes en los cuales no podíamos utilizar nuestros propios lenguajes, ni él el suyo físico porque yo no lo entendía, ni yo el mío, porque muchas veces él no podía seguirme, pero lográbamos encontrar lenguajes intermedios, dándonos cuenta así de que muchas veces estábamos en territorios paralelos. Esto mismo me ha sucedido también con biólogos y filósofos. Por ejemplo, a Heidegger le conocí en una exposición mía en un museo en Zürich. [Nota de la autora: En realidad se conocieron en la exposición en St. Gallen.] Recorrimos la sala juntos, haciéndome él mil preguntas sobre las obras y sus títulos.» CHILLIDA, E., Escritos, Madrid, La Fábrica, 2005, pp. 82-83.

En el pasaje citado, Chillida hace referencia a la afinidad de pensamiento que el escultor encontró con Heidegger. Resalta las largas conversaciones y el intenso intercambio intelectual que tuvo con el primero. Esto son cosas donde la memoria difícilmente falla a diferencia de datos puntuales, como fechas, duraciones, cronologías exactas y lugares precisos, que uno puede confundir con facilidad en la medida en la que pasa el tiempo. Lo último vale todavía más para una persona que, como Chillida, valoraba mucho los encuentros humanos e intelectuales, pero que daba muy poca importancia — se podría decir incluso casi ninguna— a dataciones exactas. 
Jürg Janett, que dirigían conjuntamente la Galerie im Erker en St. Gallen. Los galeristas conocían bien al filósofo alemán que frecuentaba desde hacía años la galería y que tenía una estrecha y larga amistad con Dino Larese, el hermano de Franz Larese. Para entender el origen de este extraordinario proyecto hay que mencionar la historia previa de los libros de bibliófilo que se hacían por aquellos años en el taller de la empresa Erker en St. Gallen, que contaba con tres negocios: una galería, una editorial y una imprenta.

Franz Larese y Jürg Janett crearon la Galerie im Erker en St. Gallen en el año 1958. Al trasladar la galería en 1963 a una casa más grande, el así llamado edificio Haus zur Wahrheit en la plaza Gallusplatz, aprovecharon los espacios traseros para abrir un taller que disponía de prensas manuales, grandes piedras litográficas y todo lo necesario para que los artistas de la galería pudieran producir in situ obras gráficas originales. Así se creó la imprenta de la Erker-Presse, y junto a ella se abrió el tercer negocio de la empresa: la editorial Erker-Verlag que publicaba pequeños libros, grandes carpetas de gráficos, y a partir de 1968 también libros de bibliófilo de diferentes tamaños, en los que los artistas de la galería colaboraban con escritores, poetas y filósofos. La producción material de los libros se realizaba en la imprenta de la Erker-Presse. En sus talleres, los artistas creaban la parte gráfica que les correspondía del libro, mientras que los autores de la parte escrita plasmaban sus textos con su propia letra en piedras litográficas, como lo haría también Heidegger en 1969 con su texto El arte y el espacio.

Los primeros dos libros de bibliófilo que se crearon en la Erker-Presse se presentaron al público en 1968. El primero, La nuit grandissante, tenía un tamaño de 47 x $34 \mathrm{~cm}$ y contaba con una tirada de 140 ejemplares numerados. Contenía un texto del poeta y escritor francés Jacques Dupin y once litografías originales de color del artista español-catalán Antoni Tàpies. El segundo libro de bibliófilo de la Erker-Presse era Meditation in Kastilien. Igualmente de gran tamaño $(46,5 \times 39 \mathrm{~cm})$ y con una tirada de 145 ejemplares numerados, constaba de poemas del escritor austriaco Max Hölzer y de siete litografías originales en blanco y negro creadas por Eduardo Chillida. Esta fue la obra que se presentó el 23 de noviembre de 1968, cuando se inauguró la exposición de Chillida en la Galerie im Erker, en la que el artista conoció a Heidegger. El tercer libro de bibliófilo, realizado en la Erker-Presse y editado por el Erker-Verlag en 1969, fue Die Kunst und der Raum que se componía de un ensayo escrito por Heidegger y de siete lito-collages y una litografía creadas por Chillida.

Como dijimos antes, Heidegger le propuso a Chillida la idea del libro cuando se vieron por primera vez. El último aceptó inmediatamente, y a consecuencia de ello, Heidegger elaboró su ensayo para el libro. Es importante resaltar que, a diferencia de lo que sostiene Heinrich Wiegand Petzet en su libro Auf einen Stern zugehen, el breve texto sobre el arte y el espacio no fue escrito de inmediato y ni siquiera en un plazo corto ${ }^{4}$. Según cuenta Petzet en el capítulo «La escultura:

4 Petzet, H. W., Auf einen Stern zugehen. Begegnungen und Gespräche mit Martin Heidegger 1929-1976, Fráncfort del Meno, Societäts-Verlag, 1983, p. 167. 
Wimmer y Chillida», Heidegger se mostró muy interesado cuando aquél le habló por primera vez de Chillida ${ }^{5}$. El libro de Petzet representa hasta ahora la fuente más citada - y a veces la única usada - en los estudios académicos que han hecho referencia al encuentro y a la colaboración entre Chillida y Heidegger. Las líneas que Petzet dedica al encuentro y al tipo de intercambio entre los dos contienen, sin embargo, graves errores. Petzet cuenta que la Galerie im Erker invitó a Heidegger al castillo Hagenwil y que el filósofo aceptó encantado la invitación, puesto que quería conocer a Chillida. En realidad, la primera conversación con Chillida fue en la exposición que hemos mencionado. La visita al castillo Hagenwil, donde hubo una cena con muchos invitados más, aparte de Heidegger, Chillida, Franz Larese y Janett —entre ellos Max Hölzer, Eugène Ionesco, Jacques Dupin, Pilar Belzunce, Guiomar Chillida, Dino Larese, Erhart Kästner-, se hizo en la noche tras la inauguración de la exposición en St. Gallen. Cabe aclarar que el Schloss Hagenwil se encuentra en Amriswil, a unos $20 \mathrm{~km}$ de St. Gallen. En sus grandes salas y comedores, los galeristas de la Galerie im Erker celebraban a menudo cenas y fiestas con artistas, intelectuales y otros personajes destacados de la cultura, ciencia y política. Estos encuentros festivos,

5 Petzet afirma que él se encontró con Chillida «por primera vez en la primavera de 1962 en su gran exposición en Zúrich» y sostiene que «pronto» pudo «contarle con todo detalle a Heidegger de una larga conversación con el artista», puesto que le parecía que «había toda una serie de relaciones asombrosas entre el pensamiento y la creación de ambos.» (Ibíd., p. 165, trad. mía) A continuación, Petzet reproduce el relato detallado que, según sostiene, le hizo a Heidegger en ese momento - en 1962 - sobre las preguntas que él le había hecho al artista en aquella conversación y sobre la manera en la que Chillida entendía el problema de espacio y tiempo. Petzet afirma que este relato fue lo que suscitó el interés de Heidegger en Chillida. En este sentido resalta: «Tanta riqueza de conexiones suscitó en Heidegger un perdurable interés - y supuso una gran alegría para él el hecho de que pudiera encontrarse en 1968, por invitación de la Galerie im Erker, con el escultor en el castillo de Hagenwil.» (Ibid., p. 166, trad. mía)

Ahora bien, hay graves incongruencias y errores en el relato de Petzet, que contradicen su afirmación de que el relato que le hizo a Heidegger se hubiera producido antes de que Heidegger conociera a Chillida. En primer lugar, la gran exposición de Chillida en Zúrich no fue en el año 1962, como sostiene Petzet - y como repiten algunos autores que siguen su relato sin verificar los datos-, sino en la primavera de 1969. La exposición en el Kunsthaus Zürich, que mostró 48 esculturas, 26 dibujos y 21 obras gráficas, se celebró del 8 de marzo al 13 de abril del año 1969 - icuatro meses y medio después de que Heidegger conociera a Chillida! En 1962 había, sin embargo, una exposición de Chillida en Basilea. Entre el 3 de marzo y el 8 de abril de ese año, la Kunsthalle Basel mostró obras de Chillida junto con obras de Mark Rothko. Puede que Petzet haya visto esa exposición y que le haya contado a Heidegger de la misma en 1962. Pero no pudo haberle contado en aquel momento a Heidegger de la conversación con Chillida, tal y como la cita en su libro. Pues ésta se realizó en marzo de 1969 en el marco de la gran exposición de Chillida en Zúrich. Prueba de ello es un artículo que Petzet publicó el 21/22 de marzo de 1969 en el periódico alemán Handelsblatt bajo el título «Plastik im maßlosen Raum. Gespräch mit Eduardo Chillida in Zürich» (= «Escultura en espacio sin medida. Conversación con Eduardo Chillida en Zurich»). El artículo contiene frases y pasajes enteros que Petzet reproduce literalmente años después en el capítulo citado del libro Auf einen Stern zugehen. Cf. Petzet, H. W., «Plastik im maßlosen Raum. Gespräch mit Eduardo Chillida in Zürich», en: Handelsblatt, viernes/sábado, 21/22 de marzo de 1969, p. 23. 
que solían tener un ambiente alegre y distendido, se hacían también tras las inauguraciones de exposiciones, como ocurrió el 23 de noviembre de 1968, el día que se inauguró la exposición de Chillida. Ahora bien, Petzet, que admite no haber estado presente en Hagenwil, cuenta que el «intercambio mutuo de ideas» (gegenseitige Gedankenaustausch) entre Chillida y Heidegger, el cual se produjo, según él, en el castillo, le llevó al último a escribir en St. Gallen su ensayo sobre «El arte y el espacio» y que volvió "contento con lo hecho» a Friburgo. Según Petzet, el escultor y el pensador «se habían entendido sin muchas palabras» ${ }^{6}$.

Aparte de que Petzet se equivoca al decir que hubo un entendimiento «sin muchas palabras», hay que resaltar que el autor comete otra apreciación errónea. Pues a continuación afirma que el filósofo mandó al artista el pequeño ensayo a finales de noviembre de 1968. La inauguración de la exposición en la Galerie im Erker y la posterior fiesta en el castillo se había celebrado el 23 de noviembre. Si Petzet se hubiera fijado en la fecha, seguramente no se habría apresurado en afirmar que el texto estaba listo ya a finales de noviembre, esto es, unos pocos días tras el encuentro, algo que ya a primera vista resulta inverosímil ${ }^{7}$. Efectivamente no fue así. Es más, el ensayo no estaba terminado ni siquiera tres meses después, como evidencia una carta del 23 de enero de 1969, que Franz Larese mandó a Chillida y en la que el primero afirma que Heidegger todavía no le había enviado el texto ${ }^{8}$.

Como mostraremos en este artículo, Heidegger elaboró su ensayo sobre el arte y el espacio durante meses, y en ese tiempo el texto pasó por diferentes fases, tal y como evidencian las distintas versiones que existen del mismo. Durante todo el periodo en el que se creó el libro, Heidegger se mostró sumamente interesado en las reflexiones de Chillida. Las tomó muy en cuenta y las estudió con detenimiento en el contexto del ensayo que estaba escribiendo. Chillida, por su lado, se enfrentó en aquella época por primera vez con el pensamiento heideggeriano, con el que sintió de inmediato una cierta familiaridad. Tras el primer encuentro con el filósofo leyó y estudió escogidas obras de Heidegger, algunas en español y otras en una versión francesa, puesto que Chillida entendía muy bien el francés, pero no tenía conocimientos de alemán. En su biblioteca privada se encuentran libros de Heidegger, en los que el artista dejó marcas y resaltó pasajes en color. Entre estos libros están las obras Le principe de raison ${ }^{9}$,

6 Ibid., p. 166 (mi trad.).

7 En la versión española del libro de Petzet, se dice — tal vez para subsanar el error- que Heidegger le mandó su ensayo a finales de noviembre de 1969, lo cual de nuevo es un claro error, pues el libro de artistas se publica un mes antes, en octubre de 1969. Petzet, H. W., Encuentros y diálogos con Martin Heidegger 1929-1976, trad. de Lorenzo Langbehn, Buenos Aires, Katz Editores, 2007, p. 207.

8 Cf. carta de Franz Larese a Eduardo Chillida del 23 de enero de 1969, que se encuentra en el archivo de la Fundación Eduaro Chillida - Pilar Belzunce.

9 Heidegger, M., Le principe de raison, trad. de André Préau, prefacio de Jean Beaufret, Paris, Gallimard, 1962 (= M. HeIDEgGer, Der Satz, vom Grund, 1957)

Doy las gracias a la familia Chillida por haberme dado acceso a la biblioteca privada de Chillida y haberme concedido el permiso de estudiarla. 
Essais et conférences ${ }^{10} \mathrm{y}$ ¿Qué significa pensar? ${ }^{11}$. Incluso muchos años después de la colaboración con Heidegger, Chillida siguió refiriéndose al pensamiento del filósofo alemán, como demuestra la integración de diferentes citas heideggerianas en algunas de sus obras gráficas, así como los diferentes homenajes artísticos gráficos y escultóricos-que le hizo al filósofo a partir de 1970.

Pero el primer fruto que nació de la mutua inspiración y del intercambio intelectual entre Heidegger y Chillida fue, como ya hemos indicado, la obra conjunta Die Kunst und der Raum, que el Erker-Verlag editó en 1969. Se trata de un libro mucho más pequeño y de apariencia menos vistosa que los dos primeros. Con sus $21,5 \times 16 \mathrm{~cm}$ tenía un aspecto íntimo, más acorde con una reflexión detenida y persistente, como la que había estado a la base del proceso de creación de la obra conjunta. De hecho, las dimensiones del libro tienen una relación interna con el pensamiento de Heidegger, así como con el intercambio intelectual entre el filósofo y el artista, como muestra la siguiente anécdota. La iniciativa vino de Chillida que le propuso a Heidegger hacer el libro en el formato de los cuadernos que el filósofo solía usar para apuntar sus reflexiones. Chillida vería tal vez al filósofo anotarse algunas ideas en uno de estos cuadernos. El caso es que existen apuntes de Heidegger que hacen referencia expresa a la obra y las reflexiones de Chillida. En el archivo de Marbach, donde se encuentra el legado de Heidegger, se conservan tres hojas con apuntes de Heidegger, que el filósofo escribió a mano y que llevan en la cabecera el título «Chillida». Las hojas tienen el mismo formato que el libro Die Kunst und der Raum. Heidegger, a quien había sorprendido, según Chillida, «agradablemente esta proposición», había aceptado la insólita propuesta ${ }^{12}$.

10 Heidegger, M., Essais et conférences, trad. de André Préau, prefacio de Jean Beaufret, Paris, Gallimard, 1958 (= M. HeIDEGGER, Vorträge und Aufsätze, 1954).

11 Heidegger, M., ¿Qué significa pensar?, trad. de Haraldo Kahnemann, Buenos Aires, Nova, 1958. (= M. HeidegGer, «Was heißt Denken?», 1951-52).

12 Con respecto a la decisión de hacer el libro en el formato de los cuadernos de apuntes de Heidegger, Chillida recuerda la siguiente anécdota: «[...] me propuso hacer un libro de bibliófilo con un escrito suyo y un tiraje limitado. Acepté, y una de las cosas que más le chocaron fue que le preguntara cuál era el formato donde plasmaba todas sus ideas. Le contesté que me parecía lógico que el libro donde íbamos a colaborar tuviera esa misma dimensión. A él le sorprendió agradablemente esta proposición, pero no así al editor, que estaba interesado en hacer un libro de gran formato. Fue un encuentro que me aportó mucho.» CHILlida, E., Escritos, op. cit., 83. Con gran seguridad, Chillida le hizo a Heidegger la propuesta del formato cuando se conocieron, esto es, el 23 de noviembre de 1968, o bien al día siguiente. Pues en la carta antes citada (redactada en francés), que Franz Larese le mandó a Chillda dos meses después, el 23 de enero de 1969, el galerista asegura que «el formato del libro se basará en el formato de páginas del manuscrito del profesor Heidegger» (trad. mía). Chillida y Heidegger no se habían visto de nuevo en esos dos meses y tampoco habían mantenido una correspondencia epistolar. 


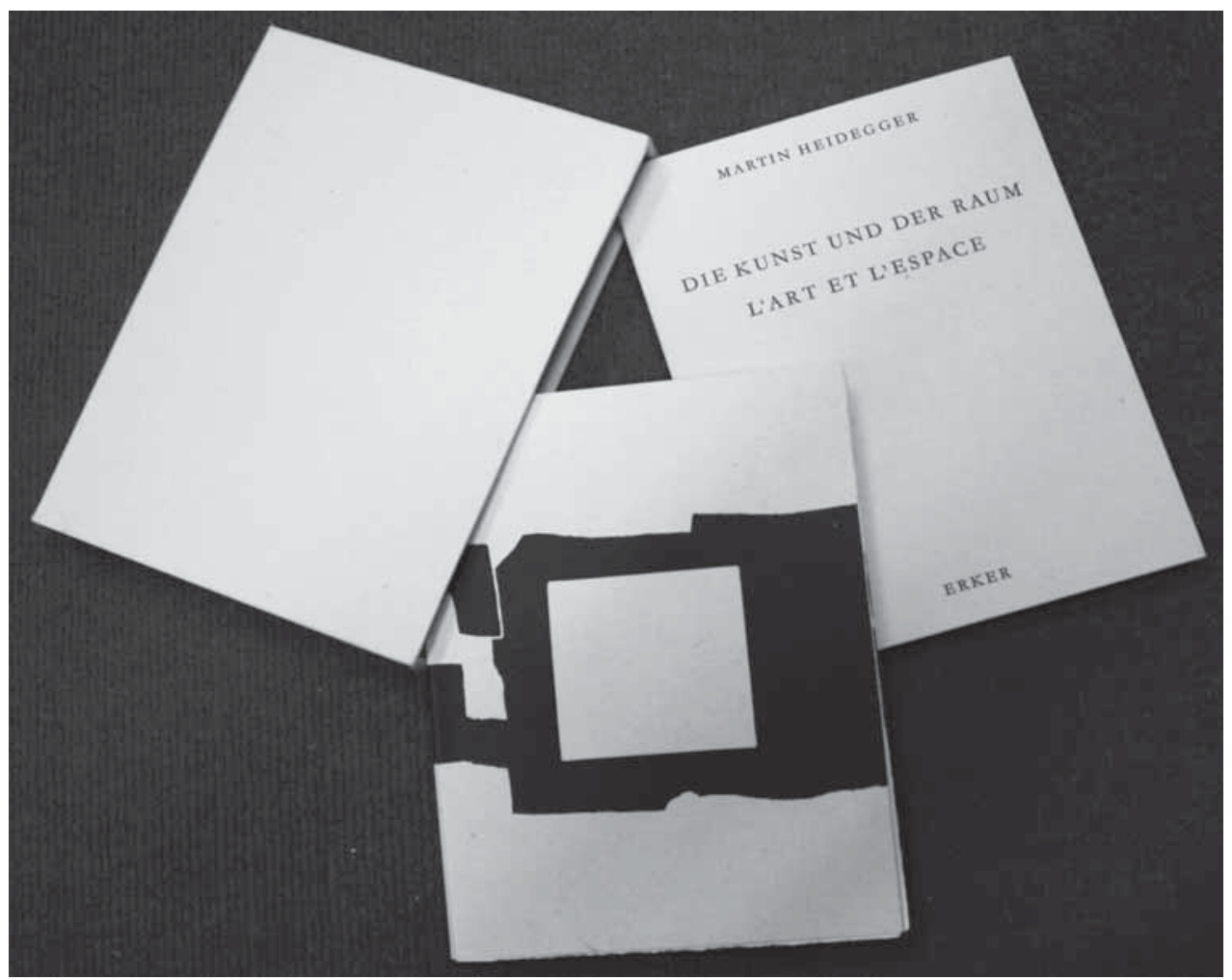

Ilus.1: Caja y cubiertas del libro de bibliófilo Die Kunst und der Raum - L'art et l'espace de M. Heidegger y E. Chillida, Foto: A. M. Rabe

\section{EsPacio, TIEMPo y ARTE EN HEIDEgGER y CHILlidA}

La pregunta de la que se quería ocupar Heidegger en su ensayo para el libro de bibliófilo concernía el espacio, en concreto un espacio ligado al tiempo en relación con el arte. El filósofo, que ya había tratado esta pregunta en relación con el Dasein del hombre en un capítulo de su obra temprana Ser y Tiempo de 1927, estaba dándole en los años 60 mayor protagonismo al problema del espacio. En este sentido resalta al final de su conferencia Tiempo y Ser, presentada el 31 de enero de 1969 en la Universidad de Friburgo, la necesidad de repensar el espacio, y junto al espacio, el lugar. Teniendo en cuenta que hay que reflexionar sobre la «relación del espacio con el acontecimiento», para lo cual es necesario «reconocer antes el origen del espacio desde lo propio del lugar», Heidegger concluye que no se puede «mantener el intento en "Ser y Tiempo" § 70 de deducir la espacialidad del Dasein de la temporalidad.» ${ }^{13}$

13 Heidegger, M., «Zeit und Sein», en: Heidegger, M., Zur Sache des Denkens, Tubinga, Max Niemeyer, 1969, pp. 1-25, cita: p. 24 (mi trad.). 
Ahora bien, el interés de relacionar el espacio - y el tiempo- con el arte se manifestó ya mucho antes de que Heidegger le propusiera a Chillida el libro sobre El arte y el espacio. En 1964, los galeristas de la Galerie im Erker le habían invitado a hablar en una exposición que se inauguraba el 3 de octubre. El filósofo aprovechó la ocasión para presentar por primera vez en público sus reflexiones sobre el arte, la escultura y el espacio. Se inauguraba una exposición del escultor alemán Bernhard Heiliger que era miembro, como Heidegger, de la Academia de Artes de Berlín. El texto que Heidegger leyó aquel día y que fue publicado en 1996 en el Erker-Verlag tenía por título Bemerkungen zu KunstPlastik - Raum (= Observaciones sobre arte - plástica - espacio). Aparte de una breve alusión a las «cabezas» escultóricas de Heiliger no había en el discurso del filósofo ninguna referencia más a la obra o al pensamiento del $\operatorname{artista}^{14}$. Sin embargo, lo que el discurso muestra con toda claridad, es el deseo del filósofo de abordar la pregunta por el espacio prescindiendo de las representaciones abstractas de la física, como la extensión, la medida o el dualismo entre cuerpo y espacio. Al caracterizar el espacio como lo que «espacia» (räumen) y lo que «da libre» (freigeben), Heidegger resalta su sentido activo y temporal y le concede una importancia fundamental para la vida humana ${ }^{15}$.

Del espacio en relación con el tiempo y con el Dasein se ocupó Heidegger por aquellos años también en los seminarios que impartía con una periodicidad variable entre 1959 y 1969 en la casa privada del psiquiatra Medard Boss en Zollikon, a unos $90 \mathrm{~km}$ de St. Gallen. En esas clases para médicos y psiquiatras, de las que se hicieron protocolos y estenografías, Heidegger centró en varias ocasiones su atención en la unión directa entre el ser del hombre y el «ahí», esto es, en la dimensión espacial sin la cual el hombre no puede vivir. La unión entre «ser» (Sein) y "ahí» (da) se refleja en la palabra Dasein que caracteriza la existencia del hombre y que ya fue un concepto clave en su obra temprana Ser y Tiempo. En las clases en Zollikon, publicadas en 1987 por Medard Boss bajo el título Seminarios de Zollikon, Heidegger retoma este concepto y resalta su condición espacial introduciendo un guión en la palabra. El Da-sein, la existencia del ser humano, es esencialmente abierto, tal y como indica el da -el «ahí»— en el que se desenvuelve el ser. Ese «estar abierto a» (Offenheit) tiene, como resalta Heidegger, «el carácter del espacio.» ${ }^{16} \mathrm{El}$ hecho de que el Da-sein sea fundamentalmente espacial, sin embargo, no sólo significa que la condición de la existencia humana - y de su libertad - consista en un «estar abierto a», sino también que el hombre debe encontrar su lugar en la tierra. Al preguntar por un espacio que no está «dado» de antemano, sino que el hombre tiene que buscar, formar y mantener abierto para poder encontrar su lugar,

14 Heidegger, M., Bemerkungen zu Kunst - Plastik - Raum, ed. por Hermann Heidegger, St. Gallen, Erker-Verlag, 1996, p. 14.

15 Ibíd., p. 13

16 Heidegger, M., Zollikoner Seminare. Protokolle-Zwiegespräche-Briefe, ed. por Medard Boss, Fráncfort del Meno, Klostermann, 2006, p. 188 (mi trad.). 
Heidegger hace referencia a los conceptos aristotélicos de $\tau$ tó $о \varsigma$ у $\chi \dot{\omega} \rho \alpha .{ }^{17}$ En este sentido afirma el 5 de noviembre de 1964 en una clase en Zollikon que «el espacio tiene el carácter de lo que acoge, que concede a cada cosa su lugar, el espacio abraza lo que la cosa corporal deja fuera de sus límites [Ausgegrenzte], lo concedido por él mismo.» ${ }^{18}$

¿Pero qué le lleva a Heidegger a relacionar el espacio con el arte? El espacio que le interesa no tiene, desde luego, nada que ver con la ciencia, la cual «no se mueve en la dimensión de la filosofía», como resalta el 17 de septiembre de 1969 en una entrevista para la televisión alemana, pero que «necesita, sin que lo sepa, esta dimensión». ${ }^{19}$ A continuación, Heidegger aclara por qué la ciencia necesita la filosofía dando como ejemplo el problema de espacio y tiempo:

La física se mueve en espacio y tiempo y movimiento. Lo que es movimiento, lo que es espacio, lo que es tiempo no lo puede decidir la ciencia como ciencia. La ciencia, por tanto, no piensa, no puede en este sentido pensar en absoluto con sus métodos. ${ }^{20}$

Heidegger considera el espacio como algo indeterminable e indefinible, y por tanto, como algo que se escapa de las pretensiones de la ciencia. Al mismo tiempo es, sin embargo, una pregunta ineludible. El espacio tiene una importancia fundamental para la vida humana, y en este sentido tiene que ser pensado. Pero no debe encerrarse en una concepción concluyente y definitiva, sino que debe mostrarse en la actividad de un pensar abierto, lo cual supone una profunda experiencia. ¿Mas cómo lograr esa experiencia? Heidegger piensa que el arte podría ayudar a abrir el camino a la experiencia del espacio, que a la vez es una experiencia del tiempo. Lo que debe hacer el arte -el verdadero arte, esto es, un arte capaz de hacer ocurrir la verdad- es abrir la posibilidad de que el secreto del Dasein se manifieste en la experiencia y que se revele así - en la experiencia - la verdadera condición de la existencia humana. Si Heidegger piensa que esta revelación debe ocurrir en la experiencia, es porque está convencido de que la racionalidad moderna, dominada por el tecnicismo y la cibernética, esto es, por un pensamiento pragmático y utilitario, es incapaz de abandonar el deseo de control y de entregarse al secreto (Geheimnis).

Ahora bien, si la ciencia y la técnica, que dominan la vida y el pensamiento moderno, no pueden abrir el camino al secreto, debe hacerlo una fuerza diferente que sea capaz de impactar al hombre de otra manera y ofrecerle lo que la racionalidad moderna no puede proporcionar. Desde luego, Heidegger piensa aquí, en primera instancia, en la capacidad del pensar. Ciertamente

17 Ibíd., p. 39-40. Heidegger se refiere también en la conferencia de 1964 en St. Gallen a estos conceptos aristotélicos.

18 Ibid., p. 40 (mi trad.).

19 Heidegger, M., «Martin Heidegger im Gespräch (17. September 1969)», en: HeidegGer, M., Reden und andere Zeugnisse eines Lebensweges, 1910-1976 (= Gesamtausgabe, I. Abteilung: Veröffentlichte Schriften 1910-1976, Bd. 16), ed. por Hermann Heidegger, Fráncfort del Meno, Vittorio Klostermann, 2000, pp. 702-710, cita: p. 705 (mi trad.).

20 Ibid, p. 705 (mi trad.). 
no se trata de un pensamiento que pretende proporcionar «sabidurías de la vida aprovechables», como resalta Heidegger en su conferencia Tiempo y Ser de 1962, sino en la capacidad de "pensar algo ineludible, pero preliminar» ${ }^{21}$. Para ello se requiere una reflexión activa, abierta, que no tema lanzarse a lo incierto, pero que también sepa escuchar. Se trata, pues, de un pensar en el espacio, esto es, un pensar abierto a lo incierto e incontrolable, igual que de un pensar en el tiempo, en el presente, esto es, un pensar que deje que se presenten (Anwesenlassen) las cosas - y con ellas el ser ${ }^{22}$. El pensar que Heidegger tiene

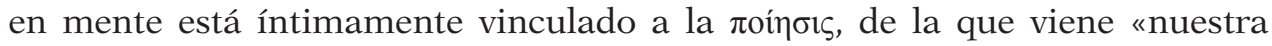
palabra poesía, Dichtung», como resalta el filósofo en la conferencia en St. Gallen de $1964^{23}$. Pasando de la poesía al arte en general, afirma que «[t]odo arte es, cada uno a su manera, Dichtung ${ }^{24}$.

Como poesía, el arte puede aliarse, por tanto, con el pensar y salirse del ámbito de la poderosa influencia del tecnicismo y de la cibernética que domina la racionalidad moderna. Puede contribuir así a que se abra el camino a una experiencia profunda de lo «desoculto»(Unverborgene). En este sentido termina Heidegger su conferencia de 1964 sosteniendo que «[m]ás filosófico que la ciencia y más riguroso, es decir, más cercano a la esencia de la cosa, —es el arte. ${ }^{25}$ Pero no todo arte, al menos no todo lo que se considera «arte» en la era moderna, es filosófico. El arte en el que está pensando Heidegger, cuando

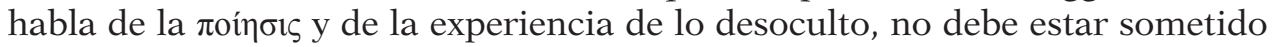
a las directrices y reglas de la gran «empresa de la cultura», del Kulturbetrieb, que ha engullido en los tiempos modernos tantas tendencias y producciones $\operatorname{artísticas~}^{26}$.

Teniendo en cuenta las esperanzas que Heidegger albergaba con respecto al arte, pero también las reservas que tenía frente a las condiciones y los mecanismos actuales del arte, podemos suponer que le gustaría, por un lado, la propuesta de los galeristas de hacer un libro en colaboración con un artista, pero que sentiría, por otro lado, la necesidad de encontrar a un artista que estuviera alejado de los mecanismos y las pautas del Kulturbetrieb y que pudiera cumplir sus expectativas. En este contexto preciso hay que situar el

21 Heidegger, M., «Zeit und Sein», op. cit., p. 1 (mi trad.).

22 Ibid., p. 5. Cf. la cita en la misma página, donde Heidegger resalta que el pensar tiene que pensar incluso el mismo dejar que se presente (Anwesenlassen).

23 Heidegger, M., Bemerkungen zu Kunst - Plastik - Raum, op. cit., p. 16. (mi trad.). Dichtung es la palabra alemana por «poesía».

${ }^{24}$ Ibid., p. 16 (mi trad.).

25 Ibid., p. 16. (mi trad.).

26 En su discurso ante la Academia de las Ciencias y Artes en Atenas en el año 1967, Heidegger formula con toda claridad sus reservas respecto a un arte moderno ligado a las «informaciones en el circuito regulador de la sociedad industrial y del mundo científicotécnico», desde el cual «la tan citada "empresa de la cultura" obtiene incluso su fundamento legítimo». Heidegger, M., «Die Herkunft der Kunst und die Bestimmung des Denkens», en: Heidegger, M., Denkerfahrungen 1910-1976, Fráncfort del Meno, Klostermann, 1983, pp. 135149, cita: p. 146 (mi trad.). 
encuentro con Chillida en la exposición de la Galerie im Erker. El hecho de que se conocieran en aquella ocasión no es, desde luego, ninguna coincidencia. Heidegger ya había oído hablar del escultor español y lo había considerado como un posible candidato para el proyecto del libro. Según cuenta Chillida en la entrevista con Ugalde, Heidegger «estaba escribiendo sobre el espacio» y

al tocar los temas del espacio se interesó mucho por el arte, por la escultura, por la arquitectura; [...] [Heidegger] había pedido documentación sobre Moore, el famoso escultor inglés; sobre Giacometti; algunos más, y entre éstos estaba yo. ${ }^{27}$

Tal y como sigue relatando, él —Chillida - se enteró de esta circunstancia, y un año después le presentaron a Heidegger en la exposición de la Galerie im Erker en St. Gallen. El artista resalta que los dos hablaron

largo rato, y [Heidegger] debió quedar interesado por algunos puntos que tocamos, porque al cabo de unas semanas recibí una carta del editor diciendo que le gustaría mucho ver algunas notas mías que yo le había citado sobre los temas de "tiempo" y "espacio"... ${ }^{28}$

El encuentro y la conversación con Chillida dejó, efectivamente, una impresión tan fuerte en Heidegger que éste le pidió a través de Franz Larese que le mandara todo lo que hubiera escrito sobre el espacio. El 23 de enero de 1969, dos meses después del encuentro entre Chillida y Heidegger en St. Gallen, le llegó al primero una carta de parte de Franz Larese, que rezaba en el posdata:

Ayez la bonté de me faire parvenir le plus tôt possible tout ce que vous avez écrit vous-même su sujet de l'espace. Le professeur Heidegger s'y intéresse beaucoup.

[Tendría la bondad de hacerme llegar lo antes posible todo lo que usted mismo haya escrito sobre el tema del espacio. Al profesor Heidegger le interesa mucho. $]^{29}$

La carta citada revela el profundo interés que Heidegger mostró por el pensamiento de Chillida y especialmente por su idea de espacio y tiempo. El filósofo reconocería ya en el primer encuentro muchas de sus propias preguntas en las cuestiones que le comunicaba el artista. Pero seguro que no era la mera coincidencia de ideas lo que le llamaría la atención y le motivaría a profundizar el intercambio iniciado. Más peso tendría el hecho de que aquellas reflexiones y preguntas provenían de un escultor, esto es, de alguien que había llegado a ellas en su praxis artística. Igual que Heidegger, Chillida se oponía al concepto abstracto de las ciencias naturales concibiendo el espacio como algo vivo, inseparable del tiempo y del ser del hombre, que no está simplemente

27 Ugalde, M. DE, Hablando con Chillida, op. cit., p. 96.

28 Ibid., p. 97.

29 Cita del postdata de la carta de Franz Larese a Eduardo Chillida del 23 de enero de 1969, que se encuentra en el archivo de la Fundación Eduardo Chillida - Pilar Belzunce. 
"dado», sino que es un secreto - algo desconocido- que hay que buscar. En este sentido anota Chillida:

Yo me paso la vida buscando en mi estudio - mi lugar favorito- para intentar aproximarme a lo que desconozco. Ahí me he dado cuenta de que existe el tiempo en mi escultura. Existe en una versión que no es la versión temporal corriente. Es la de un hermano del tiempo: el espacio. El espacio es un hermano gemelo del tiempo. Son dos conceptos absolutamente paralelos y similares. Y como yo estoy muy condicionado por el espacio, he estado siempre muy interesado por el tiempo. De hecho, mi tiempo es muy lento; pero ese tiempo es el del reloj, que es el que a mí no me interesa. Me interesa el tiempo que es armonía, es ritmo, son medidas. ${ }^{30}$

Cada uno de los dos, el artista y el filósofo, se enfrentaba al gran reto del espacio con sus propias herramientas. Heidegger lo hacía a través de un pensamiento que consistía esencialmente en preguntar, buscar y volver a la pregunta, mientras que Chillida emprendía una creación artística en y con el espacio, el tiempo y la materia, que entendía igualmente como una búsqueda y pregunta constante ${ }^{31}$. El filósofo y el artista no sólo compartían, por tanto, el interés por el mismo problema, sino que coincidían también en la manera de tratar el problema: como pregunta y búsqueda. Ahora bien, en el caso de Chillida, ese tratamiento no sólo se manifestaba en obras escultóricas y gráficas, sino también en la palabra: en escritos, aforismos y reflexiones que contienen un alto valor poético-filosófico.

Heidegger reconoció inmediatamente que este artista-pensador podía confirmar y fortalecer su intuición en torno a las posibilidades del arte, incluso en tiempos dominados por la cibernética que, como advertía el filósofo, las disminuía considerablemente. Como dijimos antes, Heidegger esperaba que el arte mostrara su capacidad de facilitar una experiencia profunda - verdaderade espacio y tiempo. Intuía que el arte que tuviera el potencial de hacer vivir un espacio inseparable del tiempo, podía ayudar a presentir el verdadero lugar del hombre y de la vida en la tierra: un lugar inseparable de las cosas, que lleva a un verdadero habitar, esto es, un estar con las cosas. Precisamente esto era lo que Heidegger reconoció en la obra y el pensamiento artístico de Chillida. Las obras del último invitan a estar, pero no sólo a estar junto a ellas y a contemplarlas, sino también a estar dentro, fuera, alrededor de ellas, con ellas y - a partir de ellas- con su entorno. El estar al que invitan las obras de Chillida no es estático. Implica, al contrario, una profunda experiencia espacio-temporal: requiere un moverse constante que se abre a experiencias siempre nuevas, igual que a un habitar verdadero, esto es, un habitar que le

30 Chillida, E., Escritos, op. cit., p. 53.

31 Véase las citas escogidas del cuaderno de apuntes de Chillida, que se reproducen al final de este artículo, entre ellas las siguientes: "Es bastante sencillo, todo se reduce a aprender a preguntar.» (CHILlidA, E., Schriften, Düsseldorf, Richter, 2009, p. 52); «la obra es para mí contestación y pregunta» (ibíd., p. 56); «también dentro de lo conocido se halla lo desconocido» (ibid., p.96); «Yo no represento, yo pregunto.» (ibid., p. 111). 
concede al hombre un lugar y le hace descubrir sus espacios. Esta experiencia abierta y lanzada al presente, a la que invitan las obras de Chillida, se refleja también en su pensamiento. El artista no esperaba encontrar una respuesta clara y definitiva a las preguntas que le movían. Le intrigaba el enigma de la unidad espacio-temporal, la cual hace que nada sea completamente diferente ni completamente igual, como sostenía ${ }^{32}$. Chillida estaba profundamente convencido de que en el límite dinámico - en el entre como el que se manifiesta en el diálogo entre las formas o en el estar entre la diferencia y la igualdadse encuentra la condición de todo cuanto existe en el mundo ${ }^{33}$. Al artista le interesaba la búsqueda, porque sabía que sólo en el buscar —en el movimiento mismo que transcurre en el entre, en una experiencia espacio-temporal que no se puede fijar - se muestra lo que se busca. Esta postura abierta al presente, a la búsqueda, al secreto espacio-temporal del entre concordaba perfectamente con la postura filosófica de Heidegger. Así no sorprende que el filósofo dedicara al artista, a ese buscador y preguntador incansable, al día siguiente tras el primer encuentro las siguientes palabras que escribió a mano en el taller del Erker-Press. Se trata de una auto-cita extraída del epílogo de las conferencias de Heidegger sobre El origen de la obra de arte de los años treinta:

Las siguientes reflexiones conciernen el secreto del arte, el secreto que es el arte mismo. Lejos queda la pretensión de resolver el secreto. De lo que se trata es de ver el secreto. ${ }^{34}$

32 Compárese sus hermosas palabras dedicadas a Bach, que Chillida pronuncia en su discurso de ingreso a la Real Academia de San Fernando y que se encuentran en el cuaderno de apuntes de Chillida. La cita, que también reproducimos al final del artículo, reza: «Saludo a J. S. Bach. | Moderno como las olas | antiguo como la mar | siempre nunca diferente | pero nunca siempre igual.» (Ibíd., p. 131).

33 Cf. con respecto a la importancia del entre la siguiente cita del cuaderno de apuntes de Chillida: «El diálogo entre las formas, sean cuales fueren éstas, es mucho más importante que ellas mismas.» (Ibíd., p. 71).

En su sugerente artículo sobre la obra y el pensamiento de Chillida en relación con cuatro conceptos fundamentales — «habitar», «límite», «compartir» y «horizonte»—, Ricardo Pinilla propone pensar «la exploración espacial en la obra de Chillida» a partir de lo que llama de manera acertada un "habitar el límite» que implica el pasar el límite entre el espacio abierto y el espacio interior. Pinilla, R., "Habitar el límite, compartir el horizonte», en: Escritura e imagen, vol. 10, número especial «Homenaje a Chillida. Caminos de encuentro entre el pensamiento y el arte», 2014, pp. 199-220, cita: p. 210.

${ }_{34}$ El manuscrito dedicado a Chillida está publicado en: HeIdegGer, M., Reden und andere Zeugnisse eines Lebensweges, 1910-1976, op. cit., p. 696 (mi trad.) La dedicatoria trae a continuación otra cita sacada de El origen de la obra de arte, que reza: «En ocasiones tenemos todavía la sensación de que ya desde hace tiempo se ejerce violencia contra la coseidad [Dinghaften] de las cosas y que en esta forma de actuar violenta [Gewaltsamkeit] entra en juego el pensar, por lo que se abjura del pensar en vez de procurar de que el pensar se haga más pensante» (Ibíd., p. 696, mi trad.). Debajo de las citas, el manuscrito dice: «Für Eduardo Chillida. St. Gallen, den 24. November 1968. Martin Heidegger» (= «Para Eduardo Chillida. St. Gallen, a 24 de noviembre de 1968. Martin Heidegger»). 


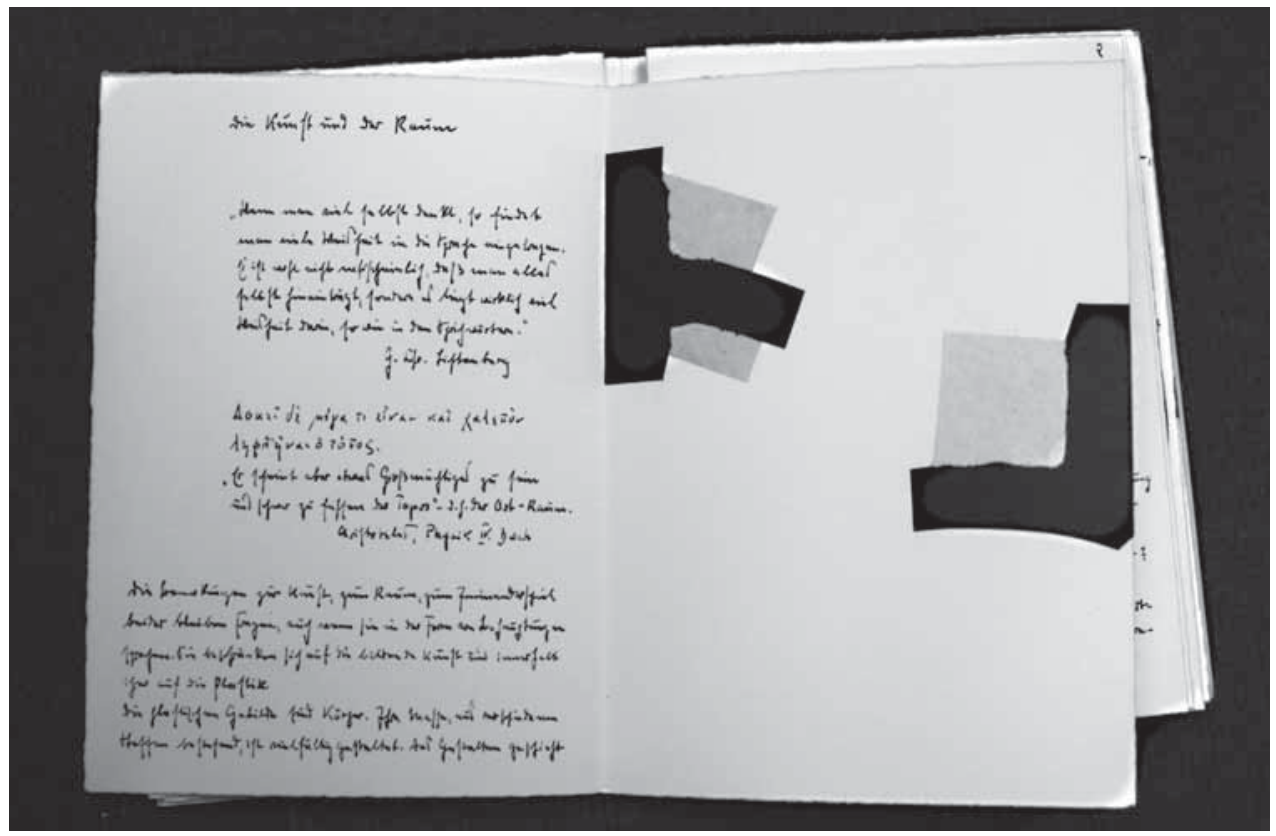

Ilus.2: Primera página del libro Die Kunst und der Raum, Foto: A. M. Rabe

\section{Conceptos Claves del ENSAyo EL ARTE Y EL ESPACIO DE HeIDEgGER Y SUS CONEXIONES CON EL PENSAMIENTO ARTíSTICO DE CHILLIDA}

Tras presentar tanto el contexto histórico como el marco filosófico de la colaboración entre Heidegger y Chillida intentaremos finalmente evidenciar con ayuda del material encontrado la importancia que tuvo para Heidegger el diálogo con el artista. Haremos referencia, por un lado, a los apuntes de Heidegger sobre Chillida, y por otro lado, a una serie de reflexiones que se encuentran en el cuaderno de apuntes de Chillida, así como a aquellas reflexiones que Heidegger usó en una traducción alemana ${ }^{35}$. Con respecto a

35 Doy las gracias al Museo Chillida-Leku, a la Fundación Eduardo Chillida - Pilar Belzunce y a la familia Chillida por el permiso de publicar los manuscritos de Eduardo Chillida, que se encuentran en el archivo de Chillida Leku.

El manuscrito mecanografiado original con las reflexiones de Chillida traducidas al alemán, que se publican aquí por primera vez, se encuentra en el «Archiv / HandschriftenLesesaal» en el Deutsches Literaturarchiv Marbach. En el manuscrito que no está fechado, las reflexiones están separadas por guiones centrados y pueden ocupar desde una sola línea hasta doce líneas. También los apuntes de Heidegger sobre Chillida, que el filósofo escribió a mano en tres páginas diferentes y que muestran todos el encabezado subrayado "Chillida» se encuentran en el archivo del Deutsches Literaturarchiv Marbach. Agradezco a Arnulf Heidegger, administrador actual del legado de Martin Heidegger, por autorizar la transcripción y permitir la publicación de los manuscritos de Martin Heidegger. La transcripción de los 
las citas traducidas cabe aclarar que es muy probable que representen sólo una parte de las reflexiones que Chillida mandó a petición de Heidegger. Esto es ciertamente una suposición, puesto que no se ha encontrado hasta el momento el manuscrito que Chillida le hizo llegar a Heidegger a través del galerista Franz Larese. Pero la selección que aparece en la traducción alemana hace pensar que Chillida mandó más reflexiones de las que aparecen en la traducción. Aunque es cierto que en el cuaderno original de Chillida las ideas son muy condensadas y tienen a menudo un carácter aforístico y poético, suelen, no obstante, estar más interconectadas y desarrolladas que en la selección de la traducción alemana. Aquí aparecen, por el contrario, entrecortadas, inconexas o sólo insinuadas, lo cual hace pensar que han sido extraídas de una recopilación más coherente y más extensa. Si se buscan las citas originales en el cuaderno de apuntes de Chillida, se observa que, efectivamente, pertenecen a párrafos más extensos y a reflexiones más desarrolladas y más coherentes. Además, en los apuntes sobre Chillida, que Heidegger escribió a mano, hay referencias claras a citas de Chillida que no se encuentran en la selección traducida, pero sí en el cuaderno de apuntes. ${ }^{36}$

A continuación se intentará mostrar en concreto y con fundamento los conceptos, las preguntas y concepciones de Chillida, que pudieron haber inspirado a Heidegger y que pudieron haber dejado incluso importantes huellas en el ensayo El arte y el espacio. Con ello no se pretende decir, desde luego, que Heidegger haya adoptado ideas ajenas. Más bien reconocería en las reflexiones de Chillida sus propias preguntas, y entendería muchas de ellas como una suerte de confirmación de sus ideas por parte de un artista. Pero en un verdadero intercambio intelectual, como el que hubo entre los dos, no se "confirman» simplemente las reflexiones que se comparten, como tampoco se «adoptan» sin más. En un verdadero diálogo, que siempre es abierto y dinámico, se produce un dar y recibir mutuo, un escuchar, retomar y volver a las propias posturas para desarrollarlas más e integrar en ellas las sugerencias e inspiraciones recibidas. En este sentido, lo que se expondrá en relación con las concepciones chillidianas, especialmente las de vacío y lugar cuyos significados se pueden reconocer en el ensayo El arte y el espacio, no es algo que le haya sido ajeno a Heidegger antes de conocer a Chillida; más bien todo lo contrario.

apuntes escritos a mano sobre Chillida supone una tarea difícil por la letra particular de Heidegger y por su costumbre de usar la escritura antigua alemana. Agradezco la gran ayuda de Almuth Heidegger — y también de Arnulf Heidegger — en la transcripción de estos apuntes de los que se publica aquí la primera página (la más extensa).

36 En los apuntes de Heidegger se lee, por ejemplo, la alusión enigmática «Raum, wie "Zimmer"» (= «espacio, como "habitación"»), la cual puede estar directamente relacionada con una cita de Chillida que reza: «Una habitación con la puerta cerrada es otra habitación, que la misma, con la puerta abierta.»(CHILlida, E., Schriften, op. cit. p. 95) Aunque esta cita no se encuentra en la selección traducida al alemán, aparece en el cuaderno de apuntes de Chillida inmediatamente después de la siguiente cita que, en cambio, sí se encuentra en la traducción alemana: «Los espacios con los que yo trabajo o son virtuales o son inaccesibles.» Es altamente probable que Chillida haya incluido la cita anterior (con la alusión a la habitación) en la selección que le hizo llegar a Heidegger. 
Pero precisamente por ello, por reconocer en aquellas concepciones profundas conexiones con sus propias ideas, Heidegger las retomó y las integró en su pensamiento para dar otro paso más en su pregunta por el espacio, por aquello que junto con el tiempo concede, en su visión, al ser humano la libertad de lo abierto, sin lo cual no hay Dasein.

Como dijimos antes, Heidegger presenta por primera vez sus reflexiones sobre el arte, la escultura y el espacio en el año 1964 en su discurso en la Galerie im Erker. En aquel discurso, Heidegger menciona más bien de pasada el problema del «lugar». Cinco años después, el filósofo ofrece de nuevo en la misma galería, esta vez por escrito, reflexiones sobre la manera en la que «entran en juego» el arte - especialmente la escultura- y el espacio. Esta vez, el concepto de «lugar» cobra un papel central. En El arte y el espacio, el ensayo del libro creado junto con Chillida, advierte el filósofo:

El entrar mutuamente en juego [Ineinanderspiel] de arte y espacio tendría que pensarse desde la experiencia de lugar [Ort $]$ y paraje [Gegend $].^{37}$

No se puede entender, según Heidegger, la relación de espacio y arte sin tener en cuenta el lugar - y junto a él el paraje; hay que pensar su significado e importancia, esto es, hay que preguntar qué es lo que convierte algo en un lugar y qué importancia tiene para el Dasein. Ahora bien, para entender la manera en la que se relacionan arte y espacio no sólo hay que tener en cuenta el concepto de «lugar». Lo que hay que considerar, según las palabras de Heidegger, es la experiencia de lugar. La experiencia, cuya importancia en relación con la pregunta por el arte aparece ya en el discurso de 1964, es algo que se realiza en movimiento, esto es, estando de camino, como indica la palabra alemana Erfahrung, la cual se compone del prefijo «er», que insinúa un proceso temporal, y del verbo «fahren», que significa «ir», «circular», etimológicamente: «dejar ir», «llevar», «andar». El sentido etimológico de la palabra Erfahrung concuerda perfectamente con la postura de Heidegger.

El estar de camino, que caracteriza la experiencia, implica un estar abierto al mundo, un lanzarse a lo incierto y abrirse a lo que pueda venir, un constante alejarse y des-alejar (ent-fernen), y con ello una continua inversión de lejanía y cercanía. Ahora bien, si el «abrir» y «estar abierto a» es una condición fundamental del Dasein, como dijimos antes, y si este «abrir» y «estar abierto a» se manifiesta en la experiencia, entonces la experiencia debe reflejar la esencia del Dasein. Pero Heidegger dice que se debe pensar en la experiencia de lugar y en la importancia que éste tiene para el Dasein. ¿Cómo entra, pues, el lugar en las consideraciones que acabamos de presentar?

Si hemos dicho que la experiencia consiste esencialmente en un abrirse y estar de camino, hay que añadir ahora que en el caminar mismo, en el abrirse, la experiencia encuentra algo. Lo que encuentra, es un lugar. Pero no

37 Heidegger, M., Die Kunst und der Raum. L'art et l'espace, Fráncfort del Meno, Klostermann, 2007, p. 11 (mi trad.). 
encuentra cualquier lugar, y desde luego no un «puesto» fijo y preexistente, sino un lugar en el que la experiencia se encuentra a sí misma como algo que se está abriendo. Con ello, la experiencia tiene una dimensión espacio-temporal fundamental. La experiencia implica, pues, el estar en un sentido tanto espacial (de lugar) como temporal (de presente), así como un abrirse que igualmente tiene el doble sentido espacio-temporal. La experiencia de lugar, que a la vez significa encontrar un lugar en la experiencia, tiene para Heidegger un sentido existencial fundamental, el cual consiste en «habitar»(wohnen). "Habitar», tal y como lo entiende Heidegger, implica hacer la experiencia de un lugar. Por tanto, no hay lugar si no se habita. Para Heidegger, habitar - encontrar un lugar en la experiencia- significa estar verdaderamente en el mundo. ¿Pero dónde se produce el habitar, si el habitar está ligado a la experiencia que se realiza fundamentalmente en el movimiento, en el caminar mismo? El problema planteado nos lleva a preguntar de nuevo por el lugar que parece haberse esfumado, sin que nos hayamos dado cuenta. Ligado a la experiencia abierta a lo desconocido que podría aparecer en el caminar, el lugar parece convertirse en algo aéreo y perderse así en el vacío.

Ahora bien, si Heidegger invita a pensar la experiencia de lugar para entender cómo entran mutuamente en juego arte y espacio, y si pensar esa experiencia parece dejar el lugar en el aire, entonces debemos volver al juego mutuo de arte y espacio y ver si la experiencia de este juego nos regala un lugar. Veamos, pues, la experiencia espacio-temporal a la que invitan las esculturas de Chillida. En el cuaderno de apuntes del artista hay una cita significativa que dice lo siguiente:

Todo es redondo alrededor de lo que gira siendo indiferente la forma de lo que gira. A la escultura se tiene acceso desde ese campo «redondo alrededor». No hay otra posibilidad. I La escultura debe siempre dar la cara y estar atenta a todo lo que alrededor de ella se mueve y la hace viva. ${ }^{38}$

Si Chillida dice que la escultura «debe estar atenta a todo lo que alrededor de ella se mueve» y si añade que aquello que se mueve alrededor de ella es lo que «la hace viva», podemos entender esta afirmación en sentidos diferentes, aunque complementarios. Chillida nos recuerda, por un lado, que la escultura no se «hace viva» - dicho de otra manera: no se vive la escultura-, si uno no se pone en movimiento y la contempla desde todos los lugares posibles que puedan estar en relación con ella. Esto implica rodearla por completo ${ }^{39}$. Así, en el camino que realiza los incontables lugares desde los que se pueden acceder a la escultura, se empieza a "vivirla» en el sentido del Erfahren. Y al vivirla,

\footnotetext{
38 Chillida, E., Schriften, op. cit., p. 67.

39 En una conversación con su hija Susana, Chillida comenta al respecto: «Una escultura es un objeto inmóvil en sí, pero no lo es si hay espectadores moviéndose a su alrededor.» (CHILlida, S. (ed.), Elogio del horizonte. Conversaciones de Eduardo Chillida con Susana Chillida, Thomas Messer, Kosme de Barañano, Roberto Herrero, José Antonio Fernández Ordóñez, Hans Spinner, Víctor Gómez Pin, Antonio Beristain, Gonzalo Suárez, Alberto Portera, Eduardo Iglesias, Barcelona, Destino, 2003, p. 23).
} 
se está con ella. Se la habita, como diría Heidegger. Ahora bien, estar con ella - habitarla - significa, a la vez, ponerse en su lugar. Aquí es donde aparece el otro sentido de la afirmación de Chillida. Estando con la escultura y poniéndose uno en su lugar, uno se abre con ella, desde su lugar, «a todo lo que alrededor de ella se mueve». Dicho de nuevo con una palabra de Heidegger: se abre un paraje (Gegend) en el que uno va encontrando lugares que dialogan con la escultura -y con ello con su lugar. Al abrirse y dialogar con todo lo que hay a su alrededor, la escultura-lugar se hace viva. Y al mismo tiempo, el dialogar de la esculturalugar hace que los lugares se relacionan entre ellos y que cobren vida en las cosas del alrededor, como ocurrió con la «cosa» que es la escultura ${ }^{40}$.

Hemos visto que en su entrar en juego con el espacio - y necesariamente también con el tiempo-, la escultura regala una experiencia que finalmente hace surgir - y permite vivir - un lugar: el lugar que es la escultura misma. Pero la experiencia de ese lugar permite, a su vez, encontrar otros lugares que se abren en el paraje alrededor de la escultura. Con ello, la escultura se convierte en un «lugar de encuentros». Así precisamente se titula una de las esculturas de Chillida, que se mostraron en la primavera de 1969 en Zúrich en la gran retrospectiva del artista. Con gran seguridad, Heidegger tomó muy en cuenta esa exposición. Y seguramente fue allí, en la Kunsthalle Zürich, donde volvería a ver a Chillida y donde le haría, según recuerda el artista, muchas preguntas sobre las reflexiones que éste le había mandado ${ }^{41}$. Retomando la idea

40 En la conferencia «Construir habitar pensar» (Bauen Wohnen Denken), que Heidegger dio el 5 de agosto de 1951 en el marco de las conversaciones en Darmstadt (Alemania) sobre «Hombre y espacio», Heidegger ya había presentado la idea de que el lugar no está antes de la «cosa». Hay ciertas «cosas» que generan un lugar, como ocurre, por ejemplo, con un puente que hace surgir un lugar el cual, por su parte, determina plazas, caminos, etc. y abre así un espacio. En este sentido, Heidegger afirma que «[e]l puente es, desde luego, una cosa sui géneris; pues congrega la cuaternidad de tal manera que le prepara [verstattet] un albergue [Stätte]. El lugar no está ya antes del puente. [...] Así, pues, el puente no se levanta sólo al erigirse en un lugar, sino que es sólo a partir del puente mismo que surge un lugar. Éste es una cosa, congrega la cuaternidad, pero congrega de una forma que le prepara a la cuaternidad un albergue. Desde este albergue se determinan plazas y caminos, por los que se concede espacio al espacio [ein Raum eingeräumt wird].» HeIDEgGer, M., "Bauen Wohnen Denken», en: Heidegger, M. Vorträge und Aufsätze, Stuttgart, Neske, 1997, pp.139-156, cita: p. 148 (mi trad.).

${ }_{41}$ En la entrevista que le hizo Martin de Ugalde a Chillida, el artista habla del profundo interés que Heidegger tuvo en sus reflexiones. Resalta, además, las coincidencias en el pensamiento de los dos, que igualmente se reflejan en muchos de los títulos de las obras de Chillida. En este sentido recuerda: «[...] a mí me pareció una osadía mandarle unas notas mías a un filósofo de la importancia de Heidegger, pero no podía negarle esta petición. Pili se encargó de pasarme estas notas a máquina. Cuando fui al cabo de dos o tres meses a St. Gallen de nuevo, volví a verlo [Chillida confunde en su relato fechas, lugares y cronologías, por lo que pudo haber sido Zúrich donde se vieron de nuevo], y para entonces había traducido las notas al alemán. Se me confirmó la idea de que este hombre no sale de su monolingüismo porque no quiere. Sabe español muy bien, puesto que me había corregido de su mano algún error de transcripción que había cometido Pili al escribírselos. Por ejemplo, a lo escrito con un dedo por mi mujer a máquina le faltaba alguna coma, un punto, y en uno de los aforismos 
de la escultura vivida como lugar que dona otros lugares, esto es, como algo que debe ser habitado de manera que se abran múltiples encuentros y formas de estar con las cosas, Heidegger propone en El arte y el espacio:

La plástica sería la corporeización [Verkörperung] de lugares que abren y preservan un paraje, y al hacerlo, mantienen reunido alrededor de sí algo que es libre [ein Freies], que concede a las cosas correspondientes un detenerse [Verweilen] y a los seres humanos un habitar en medio de las cosas. ${ }^{42}$

$\mathrm{Si}$ retomamos esta reflexión de Heidegger, seguramente inspirada en Chillida, y la relacionamos con lo que dijimos antes del problema de la desaparición de lugares en la experiencia, podemos sostener que el arte -y especialmente la escultura que trabaja con el espacio- puede hacer posible un detenerse y habitar, puesto que tiene la facultad de «corporeizar» lugares que de otra manera, al estar ligados a una experiencia abierta a lo incierto, podrían esfumarse y perderse en el vacío.

¿Pero cómo ocurre la «corporeización» de un lugar? ¿De dónde viene un lugar, dónde está antes de hacerse cuerpo? ¿Mas no es esto una pregunta absurda? Ningún lugar puede estar en algún lugar antes de ser lugar. Desde luego, no se puede decir que un lugar esté antes de ser lugar. Pero tal vez se podría sostener que el lugar que no está, lo es en potencia. Y aquella potencia, que alberga la posibilidad del lugar, es nada menos que el vacío. Teniendo la facultad de engendrar lugares, el vacío es. No es, por tanto, «nada». ¿Pero cómo y cuándo engendra lugares? Heidegger sostiene que lo hace cuando juega en la obra, esto es, en la «corporeización plástica». En este sentido sostiene en El arte y el espacio:

El vacío no es nada. Tampoco es una falta. En la corporeización plástica, el vacío juega de tal manera que dona lugares buscándolos y bosquejándolos. ${ }^{43}$

Un vacío que «juega», y que al hacerlo «busca», «bosqueja» y «dona» lugares, no puede ser, desde luego, un vacío como lo entiende la física clásica

había la palabra "tempo", dicho en el sentido que evocaba en mí la palabra, en el sentido de la medida, y él había puesto encima, de su puño y letra, una interrogación y la pregunta: "tempo" o "tiempo"... Como diciendo: a mí hay que precisarme el sentido exacto. Cuando llegué, me recibió amablemente, hasta elogiosamente, lo que a mí, delante de aquellos profesores con quienes estaba reunido en ese momento, me resultó excesivo... [Sigue un pasaje en el que Chillida confunde la cronología de los hechos.] Recibí el texto [Die Kunst und der Raum] al cabo de unos seis meses. [...] Para mí fue una sorpresa encontrar en la preocupación del filósofo alemán algunos puntos que para mí eran vitales y que estaban encarnados en mi obra. [...] Por ejemplo, los conceptos de lugar (leku), espacio lugar, localización (topos) y encuentro, límite, incluso "lugar de encuentro", son utilizados por Heidegger en este trabajo; son, como sabes, preguntas, e incluso literalmente títulos de mis obras desde mucho antes de aparecer este libro. También la forma de aproximarse al espacio comprometido en la obra: el espacio.» (Ugalde, M. de, Hablando con Chillida, op. cit., p. 97-98.)

42 Heidegger, M., Die Kunst und der Raum, op. cit., p. 11 (mi trad.).

43 Ibid., p. 12 (mi trad.). El texto original en alemán reza: «Die Leere ist nicht nichts. Sie ist auch kein Mangel. In der plastischen Verkörperung spielt die Leere in der Weise des suchend-entwerfenden Stiftens von Orten.» 
que lo identifica con un espacio homogéneo y rígido, un «continuo de puestos» cuya única función es establecer la separación entre masas y hacer medible las distancias. Para ver si el concepto de vacío como donador de lugares puede haber sido inspirado por Chillida, conviene considerar cómo entendió Heidegger el vacío antes de escribir el ensayo El arte y el espacio.

En una conferencia titulada "La cosa» (Das Ding), que Heidegger da en 1950 en la Bayerische Akademie der Schönen Künste en Múnich, el filósofo explica el vacío mediante el ejemplo de una jarra: «El vacío es lo que el recipiente acoge.» ${ }^{44}$ El vacío aparece aquí en su intrincado juego con lo pleno: vaciar es a la vez llenar. Al verter el líquido de la jarra en un vaso, se vacía la primera y se llena la segunda. Así es como el vacío hace posible el regalar y al mismo tiempo el acoger. En este sentido dice Heidegger: «En el regalar lo vertido se encuentra la esencia [west] del recipiente.» ${ }^{45}$ La idea de que el vacío «busca» $\mathrm{y}$ «dona» lugares, sin embargo, no se encuentra en esta conferencia. Tampoco aparece en la clase que Heidegger da en Zollikon en julio de 1964 y en la que el filósofo caracteriza lo vacío (das Leere) como "lo libre no ocupado» (das nicht besetzte Freie) ${ }^{46}$. Finalmente, en el discurso sobre el arte, la plástica y el espacio en la Galerie im Erker, que tiene lugar el mismo año, Heidegger ni siquiera alude al vacío. En cambio, en su ensayo para el libro creado con Chillida, el vacío no sólo es mencionado, sino que cobra una gran importancia con el sentido nuevo que adquiere al relacionarse con la donación de lugares. Este significado viene ciertamente preparado por las consideraciones anteriores que acabamos de mencionar, esto es, por la idea de que el vacío posibilita el regalar y el acoger, y de que se funda, por su lado, en lo libre ${ }^{47}$. Pero el nuevo significado que Heidegger da al vació en el ensayo El arte y el espacio, donde lo relaciona con la donación de un lugar, sin duda debe mucho al intenso estudio de la obra y del pensamiento de Chillida, así como al diálogo mantenido con el artista. Lo evidencian claramente las reflexiones de Chillida a las que Heidegger recurre en su versión alemana, los apuntes del filósofo sobre el artista, así como algunos títulos significativos de obras expuestas en la retrospectiva de Chillida en la Kunsthalle Zürich.

Empezando por lo último, el impacto de algunas obras con títulos significativos, no se puede pasar por alto el hecho de que la obra más importante y más grande de la exposición de Zúrich era Alrededor del vacío $I V$, una escultura de hierro de $180 \times 380 \times 170 \mathrm{~cm}$, que se había traído del museo de arte de Basilea. Esta gran escultura llamaba mucho la atención en la exposición. Además de ella había otro Alrededor del vacío —la variación

44 La cita en alemán es: «Die Leere ist das Fassende des Gefäßes.» Heidegger, M., «Das Ding», en: Heidegger, M. Vorträge und Aufsätze, op. cit., pp. 157-179, cita: p. 161 (mi trad.).

45 Ibid., p. 164 (mi trad.).

46 Heidegger, M., Zollikoner Seminare, op. cit., p. 17.

47 En la clase mencionada dice Heidegger: «No hay vació sin algo que es libre. Lo vacío se funda en lo libre.» («Es gibt kein Leeres ohne Freies. Das Leere gründet auf dem Freien.») Ibid., p. 17 (mi trad.). 
número III. En el contexto de nuestras consideraciones sobre el vacío hay que mencionar también dos obras tituladas Modulación del espacio, el número I y el II, así como tres obras tituladas Rumor de límites, los números I, II y IV. A Heidegger le interesarían estas obras no sólo por el juego con el espacio que se daba en ellas y los diálogos entre las formas que abrían, sino también por el título que les había dado Chillida. Como mostraremos a continuación, estos títulos añaden una nueva dimensión a las reflexiones que hemos citado antes.

Recordemos primero lo que hemos dicho sobre el juego que se produce entre la obra y el espacio, cuando un espectador hace una verdadera experiencia de la escultura convirtiéndola en un lugar. Chillida resalta que para vivir la escultura en toda su espacialidad y para darle vida, hay que rodearla. Al hacerlo se produce, según el artista, un «redondo alrededor», una expresión que Chillida usa como título para algunas obras tempranas. Como hemos visto, caminando alrededor de la escultura y poniéndose uno en el lugar de la misma se producen múltiples encuentros. Así es cómo se corporeizan los lugares, como dice Heidegger. Para Chillida, estos encuentros y lugares que van surgiendo se deben a la «modulación del espacio» que genera un «rumor de límites». Lo que insinúa el artista con estas expresiones que constituyen - como hemos vistootros títulos significativos de obras suyas, es un proceso que sólo se puede expresar metafóricamente. Chillida espera que al hacer sonar el espacio en otras tonalidades, al detenerlo mediante la creación de límites y crear así un «rumor», el espacio se convierta en algo retardado, esto es, en materia. De la misma manera, la experiencia del movimiento que realiza el «redondo alrededor» hace surgir el lugar. Ahora bien, si esto es así, entonces tiene que haber un vacío cargado de una fuerza engendradora. He aquí el vacío que contiene el lugar en potencia, un vacío que gracias a esa potencia es lleno. Emprender el movimiento «alrededor» del vacío significa, por tanto, sonsacar su capacidad engendradora. En este contexto hay que entender una de las reflexiones que Chillida envía a Heidegger, donde expresa su deseo de «definir lo tridimensional (hueco) por medio de lo tridimensional (pleno), estableciendo al mismo tiempo una especie de correlación y diálogo entre ellos. Gracias a estas correlaciones los volúmenes exteriores, a los que tenemos fácil acceso, serán nuestro guía seguro para llegar a conocer $[\ldots]$ espacios ocultos. $)^{48} \mathrm{Y}$ en otra reflexión del mismo manuscrito, que Heidegger usa en una versión alemana, el artista propone pasar de «un lado al otro del límite», esto es, de lo pleno a lo hueco y de lo hueco a lo pleno, e invita asimismo a «tener conciencia de que [el límite] une y separa lo tridimensional pleno de lo tridimensional hueco.» ${ }^{49}$

Finalmente, los apuntes que Heidegger hace sobre Chillida ${ }^{50}$ son otra evidencia clara de que el filósofo da una gran importancia a la concepción

\footnotetext{
48 Ver la cita en la parte documental de este artículo.

49 Ver la cita en la parte documental de este artículo.

50 Heidegger hace esos apuntes con gran seguridad tras haber recibido las reflexiones que Chillida le mandó.
} 
chillidiana del vacío como una potencia engendradora con la que la escultura intenta aliarse. De hecho, el concepto que más destaca en los breves apuntes es el vacío. Heidegger se refiere a él en seis ocasiones, y lo hace siempre en relación con la obra y el pensamiento de Chillida. En las primeras líneas, el filósofo escribe refiriéndose a las esculturas de Chillida: «Sus figuras espaciales | estereometría figural musical del vacío ${ }^{51}$. A la derecha de estas líneas apunta entre comillas las palabras "figuras independientes», debajo de las cuales escribe algo que parece cuestionar de inmediato estas mismas palabras: «pero "R." y L. | qué sig-nifica | esto.» ${ }^{52}$ La inicial «R.» representa con seguridad la palabra «Raum» (= «espacio») y «L.» «Leere» (= «vacío»). Preguntando por el «tipo de figuración» y de "obra» ${ }^{53}$, que son las figuras espaciales de Chillida, continúa apuntando: «re-presentación del vacío que empuja hacia dentro de la forma y se desfigura así hacia dentro del volumen plástico ${ }^{54}$. En los siguientes apuntes también se refleja el esfuerzo de Heidegger por entender con ayuda de la obra y de las reflexiones de Chillida el vacío engendrador en el que el espacio juega en la escultura. En este contexto, el filósofo resalta que no se deben considerar las esculturas de Chillida como una "representación» de algo, tal y como enfatiza al artista mismo en sus reflexiones ${ }^{55}$, sino que hay que entenderlas, más bien, como una forma que se ha cerrado alrededor del espacio, una afirmación en la que se reconoce inmediatamente la importancia que Chillida le da al «redondo alrededor» de la escultura. Retomando esta idea y asociándola con la «modulación del espacio» que, generando un «rumor de límites», ayuda a pasar el límite entre lo hueco y lo pleno, podemos entender los siguientes apuntes de Heidegger en los que escribe: «el espacio como vacío que empuja hacia la figura ${ }^{56}$. Y un poco más abajo leemos:

escultura: función del espacio I no su representación, sino

el R. ${ }^{57}$ y la forma que se ha cerrado alrededor de él I la fruta

$$
\begin{aligned}
& \text { | del brotar } \\
& \text { | del vacío }{ }^{58}
\end{aligned}
$$

La última cita que menciona el vacío pregunta por la manera en la que se presenta el vacío:

51 Todas las citas españolas de los apuntes de Heidegger son traducciones mías. El manuscrito dice en alemán: «figurale musikalische Stereometrie der Leere».

52 La cita en alemán dice: «aber "R." u. L. I was be-deutet I dies.»

53 En el manuscrito dice: «Welche Art von Gebilde? Werk? »

${ }_{54}$ La cita en alemán dice: «Dar-stellung der in die Form drängenden u. so sich ins plastische Volumen entstaltende Leere»

55 Cf. la afirmación de Chillida en su cuaderno de apuntes, que ya hemos citado antes: "Yo no represento, yo pregunto.» (CHILlidA, E., Schriften, op. cit., p. 111).

56 «der Raum als nach Gestalt drängende Leere»

57 La letra «R» de nuevo hay que leerla como la inicial de Raum (= «espacio»).

58 La cita en alemán dice: «Skulptur: Funktion des Raumes I nicht seine Darstellung, sondern I der R. u. die Form die sich um ihn geschlossen hat I die Frucht I des Aufgehens | der Leere» 
? «representación» de la nada del vacío | ningún mostrar, ninguna ilustración

¿hoy?

el re-flexionar» ${ }^{59}$.

Las referencias a las ideas de Chillida, que se encuentran en los apuntes de Heidegger, no dejan lugar a dudas de que el filósofo se interesó profundamente por el pensamiento del artista, especialmente por la manera en la que éste entendía los conceptos de lugar y vacío. Pero también hay que resaltar la clarividencia y originalidad con las que el filósofo retomó las ideas de Chillida. Reconociendo un vínculo ontológico entre «lugar» y «vacío», que sólo se encuentra implícito en el pensamiento de Chillida, Heidegger pudo dar un paso más en su pregunta por la importancia ontológica que se halla en el juego entre el arte y el espacio.

Resumiendo se puede decir que las reflexiones de Chillida llevaron a Heidegger a reconocer que el espacio se relaciona con el lugar gracias al vacío engendrador. Por otro lado podemos partir de que el ensayo que Heidegger escribió para el libro El arte y el espacio ayudó a Chillida a entender la relación ontológica entre «lugar»y «vacío». En su ensayo, Heidegger afirma con respecto a esta relación que caracteriza como «juego»:

En la corporeización plástica, el vacío juega de tal manera que dona lugares buscándolos y bosquejándolos. ${ }^{60}$

Heidegger termina sus reflexiones sobre la relación entre arte y espacio con la siguiente afirmación que resume brevemente la función e importancia de la escultura en el contexto de la pregunta por el ser:

La plástica: la corporeización de la verdad del ser en su obra que dona lugares. ${ }^{61}$

No es poco decir que la escultura corporeiza «la verdad del ser». Pero ésta no es la última palabra sobre la verdad, la pregunta que, en realidad, ha estado todo el tiempo tras las reflexiones sobre el arte y el espacio. Heidegger insinúa al final del ensayo que, si bien el arte es capaz de darle un lugar a la verdad, no es la única manera en la que ésta pueda darse. La verdad no requiere necesariamente el cuerpo ni la cosa, ni siquiera la obra. Puede «flotar» en el espíritu, estar en el aire, en el vacío, y hemos de añadir también: en la palabra. En este sentido termina Heidegger sus reflexiones con una cita de Goethe:

No siempre es necesario que lo verdadero se corporeice; ya basta con que flote por ahí espiritualmente y ocasione correspondencia, con que se balancee como sonido de campana serio y amable por los aires. ${ }^{62}$

59 La cita en alemán dice: «? "Darstellung” des Nichts der Leere | kein Zeigen, keine Abbildung | heute? | das Be-denken.»

60 Heidegger, M., Die Kunst und der Raum, op. cit., p. 12 (mi trad.).

61 Ibid., p. 13 (mi trad.).

62 Ibíd., p. 13 (mi trad.). 


\section{PARTE DOCUMENTAL}

\section{ACLARACIONES PREVIAS SOBRE LOS MANUSCRITOS}

Las citas de Chillida, que aparecen en el manuscrito 1 en el lado izquierdo de la tabla, se encuentran en un cuaderno de apuntes de Chillida. Se trata del cuaderno donde Chillida solía apuntar sus reflexiones ( $\sin$ fecharlas) y del cual sacó las citas que mandó a Heidegger. El cuaderno original se guarda en el archivo de la Fundación Eduardo Chillida - Pilar Belzunce en Chillida-Leku. Su contenido fue publicado en el libro Schriften $^{63}$ que reproduce en facsímil las páginas originales del cuaderno. Las citas que se reproducen en la tabla en cursiva son las reflexiones de Chillida, que Heidegger tradujo —o bien hizo traducir - al alemán. El manuscrito original en el que aparece la traducción alemana que Heidegger usó es una hoja mecanografiada por las dos caras. La parte delantera lleva el título «Eduardo Chillida» y el subtítulo «Gedanken» («Reflexiones»). Partiendo del supuesto que las citas traducidas al alemán sólo representan una pequeña parte del manuscrito que Chillida envió, reproduzco en el manuscrito 2 una selección más extensa de las reflexiones que aparecen en el cuaderno de apuntes. Esta selección incluye tanto los párrafos originales a los que pertenecen las citas traducidas, como también otras reflexiones relacionadas con la pregunta por el espacio y temas afines. Todas estas citas llevan una determinada marca que Chillida introdujo en algún momento en su cuaderno de apuntes ${ }^{64}$.

Para diferenciar las citas que se tradujeron al alemán de las reflexiones adicionales del cuaderno de apuntes que reproducimos en este artículo, mostraré las primeras en cursiva y las últimas en letra redonda. Las páginas de las citas españolas se refieren a las páginas del libro Schriften que contiene el facsímil del cuaderno de apuntes de Chillida.

63 Chillida, E., Schriften, op. cit..

64 En general, todas las citas que se reproducen aquí —incluidas las que fueron traducidas al alemán- están marcadas en el cuaderno de alguna manera: con la letra «H», con una cruz ( † o bien x) o bien con dos cruces. Algunas de las marcas vienen acompañadas por un punto grande rojo o negro. Las diferentes señales fueron seguramente introducidas por Chillida en distintos años para destacar las citas que querría usar en distintos contextos: en conferencias, en envíos como el que hizo a Heidegger, en discursos — como el discurso de ingreso que Chillida dio en la Real Academia de San Fernando- o en obras gráficas. Algunas de las reflexiones que aparecen en la traducción de Heidegger están señaladas con una $H$ que a veces viene acompañada por un punto rojo; otras no llevan esta letra, sino que están marcadas con una cruz de tipo † o de tipo x, o bien con dos cruces. La mayoría de las citas originales que se reproducen aquí, tanto las que se encuentran en la selección traducida por Heidegger como las que no aparecen en ella, tienen una o varias de estas señales. Entre las reflexiones que se encuentran en el cuaderno de Chillida, pero que no están en la selección traducida, hay algunas que llevan la letra $\mathrm{H}$, la cual podría ser la inicial de «Heidegger». 
En el lado derecho de la tabla presento las reflexiones traducidas al alemán. Si es verdad, como pienso, que Heidegger seleccionó unas cuantas citas entre todas las reflexiones que le mandó Chillida, se puede suponer que se orientaría en las preguntas que más le interesaban en relación con la manera en la que el arte y el espacio "entran mutuamente en juego», el problema central del ensayo que estaba escribiendo. ${ }^{65} \mathrm{Si} \mathrm{mi}$ suposición es cierta, el filósofo escogería aquellas reflexiones que más le llamarían la atención en relación con esta pregunta y en las que tal vez encontraría conexiones con su propio pensamiento. Heidegger decidiría traducir esas reflexiones puntuales para acercarlas más a su pensamiento. Menos importancia tendría para él el orden en el que quedarían las reflexiones traducidas. En cambio llama la atención la exactitud, precisión y sutileza con la que se hizo la traducción que Heidegger podía haber hecho solo o bien con ayuda del traductor que le solía acompañar en los encuentros con Chillida.

Manuscrito 1: traducción alemana de las Reflexiones de Chillida, oue Heidegger USÓ CUANDO ESCRIBIÓ EL ARTE Y EL ESPACIO ${ }^{66}$, Y CITAS ORIGINALES CORRESPONDIENTES ${ }^{67}$

En la parte izquierda de la tabla se muestran a continuación en letra cursiva las citas originales (en español) que corresponden a la traducción alemana. Algunas se reproducen con otras frases (en letra redonda) tal y como aparecen en el cuaderno de apuntes de Chillida. Se trata de frases que pueden haber formado parte del manuscrito que Chillida mandó a Heidegger.

${ }^{65}$ En la versión final de El arte y el espacio, Heidegger habla del «Ineinanderspiel von Kunst und Raum» que puede traducirse como «entrar mutuamente en juego arte y espacio» (Heidegger, M. , Die Kunst und der Raum., op. cit., p. 11).

66 El manuscrito se encuentra en el archivo del Deutsches Literaturarchiv Marbach y se reproduce aquí con el amable permiso de Arnulf Heidegger, administrador del legado de Martin Heidegger.

67 El cuaderno de apuntes original se encuentra en el archivo de Chillida Leku. Las citas se reproducen con el amable permiso de la familia Chillida. 


\begin{tabular}{|c|c|}
\hline $\begin{array}{l}\text { Manuscrito español (original) } \\
\text { de Chillida }\end{array}$ & $\begin{array}{c}\text { Manuscrito alemán (traducido) } \\
\text { de Heidegger }\end{array}$ \\
\hline $\begin{array}{l}\text { Hay un problema común en la mayor parte } \\
\text { de }{ }^{68} \text { mi obra, es éste el «espacio interior» con- } \\
\text { secuencia, y al mismo tiempo origen de los } \\
\text { volúmenes positivos exteriores. Para definir } \\
\text { estos espacios interiores, es necesario envol- } \\
\text { verlos, haciéndolos por lo tanto inaccesibles } \\
\text { para el espectador situado al exterior. Los es- } \\
\text { pacios interiores han sido siempre problema } \\
\text { y preocupación de los arquitectos, suelen ser } \\
\text { espacios de tres dimensiones definidos por } \\
\text { superficies de dos. Yo aspiro a definir lo tri- } \\
\text { dimensional (hueco) por medio de lo tridi- } \\
\text { mensional (pleno), estableciendo al mismo } \\
\text { tiempo una especie de correlación y diálogo } \\
\text { entre ellos. Gracias a estas correlaciones los } \\
\text { volúmenes exteriores, a los que tenemos fácil } \\
\text { acceso, serán nuestro guía seguro para llegar } \\
\text { a conocer, al menos en su espíritu, espacios } \\
\text { ocultos. }\end{array}$ & $\begin{array}{l}\text { Ein allgemeines Problem liegt in meinem Werk } \\
\text { (der innere Raum), Folge und gleichzeitig } \\
\text { Ursprung der positiven äusseren Räume. } \\
\text { Um diese inneren Räume zu bestimmen, } \\
\text { muss man sie einhüllen, wodurch sie dem } \\
\text { aussen stehenden Betrachter unzugänglich } \\
\text { werden. Die inneren Räume sind immer } \\
\text { Problem und Sorge des Architekten gewesen, } \\
\text { ganz allgemein sind sie dreidimensionale } \\
\text { Räume von zweidimensionalen Flächen } \\
\text { bestimmt. Ich strebe nach der Bestimmung } \\
\text { des Dreidimensionalen (Leere) durch das } \\
\text { dreidimensionale (volle) und gleichzeitig } \\
\text { nach der Herstellung einer Art Beziehung } \\
\text { und Gespräch zwischen ihnen. Dank dieser } \\
\text { Beziehung werden die äusseren Räume, zu } \\
\text { denenwirleichterZuganghaben, unsere Führer } \\
\text { zur Entdeckung derverborgenen Räume sein. }\end{array}$ \\
\hline $\begin{array}{l}\text { La semejanza existe en geometría, pero } \\
\text { no en arte. El punto en geometría no tiene } \\
\text { medida, en arte sí. (p.48) El hecho de que } \\
\text { el punto no tenga dimensión hace posible } \\
\text { la semejanza [y la geometría toda]. (p. } 91- \\
\text { 93.) [La dimensión del punto hace posible, } \\
\text { por otro lado, que la obra de arte tenga una } \\
\text { dimensión "óptima» única. }]^{69}\end{array}$ & $\begin{array}{l}\text { In der Kunst hat der Punkt eine Dimension, } \\
\text { in der Geometrie nicht. Diese Tatsache, die } \\
\text { Unausgedehntheit des Punktes, ermöglicht } \\
\text { die Gleichheit. Andererseits ermöglicht } \\
\text { die Ausdehnung des Punktes, dass das } \\
\text { Kunstwerk eine einheitliche Ausdehnung } \\
\text { habe }\end{array}$ \\
\hline $\begin{array}{l}\text { ¿Existen límites para el espíritu? } \\
\text { Gracias al espacio existen límites en el } \\
\text { mundo físico y yo puedo ser escultor. Nada } \\
\text { sería posible sin ese rumor de límites, y el } \\
\text { espacio que los permite. } \\
\text { ¿Qué clase de espacio permite los límites en } \\
\text { el mundo espiritual? (pp. } 64,67 \text { ) }\end{array}$ & $\begin{array}{l}\text { Als Folgen des Raumes bestehen Grenzen } \\
\text { in der physikalischen Welt. Welche Art von } \\
\text { Raum erlaubt die Grenzen der geistigen Welt? }\end{array}$ \\
\hline $\begin{array}{l}\text { Hay una oculta comunicación entre todo lo } \\
\text { que es próximo. (p. } 55 \text { ) }\end{array}$ & $\begin{array}{l}\text { Es gibt eine verborgene Verbindung zwischen } \\
\text { allem, was sich nah ist. }\end{array}$ \\
\hline
\end{tabular}

${ }_{68}$ Lo que se reproduce aquí en letra redonda aparece en el manuscrito original de Chillida, pero es omitido en la traducción alemana.

${ }_{69}$ Esta cita que aparece entre corchetes es una traducción mía. Es la única cita que no he encontrado en el cuaderno de apuntes de Chillida. He tomado la expresión «dimensión única» («einheitliche Ausdehnung») de la siguiente cita original de Chillida: «La obra de arte tiene una dimensión "óptima” única.» (Chillida, E., Schriften, op. cit., p. 48; reproducido también en CHILLIDA, E., Escritos, op. cit., p. 67). 
El pintor y el escultor están muy lejos entre sí. Una tercera dimensión que todo lo cambia los separa.

El punto de vista del escultor estará siempre a $90^{\circ}$ del punto de vista del pintor. El escultor encuentra los perfiles mirando siempre en profundidad. (p. 63)

Los espacios con los que yo trabajo o son virtuales o son inaccesibles.

Una habitación con la puerta cerrada, es otra habitación, que la misma, con la puerta abierta.

----

¿Es cualquier espacio que no comunica con los (espacios innombrables, como dice Novalis) una unidad espacial o se trata de parte de esa gran unidad. ${ }^{70}$

¿Hay posibilidad de colocar un espacio fuera de ella.¿No será lo que aísla también espacio con otro tempo? ${ }^{71}$ (pp. 95-96)

Sólo una de las tres dimensiones es activa (la que viene a mí desde lo lejano a través de lo próximo), pero las tres deben de serlo en potencia, alternando su actividad.

El presente ¿actividad (lugar activo) sin dimensión? (p. 92)

Pasar de un lado al otro del límite, tener conciencia de que une y separa lo tridimensional pleno de lo tridimensional hueco. (p. 92)

El límite es el verdadero protagonista del espacio, como el presente (otro límite) es el verdadero protagonista del tiempo. (p. 95)

¿Es cualquier espacio que no comunica con los (espacios innombrables, como dice Novalis) una unidad espacial o se trata de parte de esa gran unidad? (p. 95-96)

¿No será lo que aísla también espacio con otro tempo? (p. 96)
Der Gesichtspunkt des Bildhauers wird immer im Winkel von $90^{\circ}$ zum Gesichtspunkt des Malers sein. Der Bildhauer findet die Züge (Wege), indem er in die Tiefe blickt.

Die Räume, mit denen ich arbeite, sind entweder virtuell oder unzugänglich.

Nur eine der drei Dimensionen ist aktiv, die aus der Ferne durch die Nähe zu mir kommt, aberalle dreisind potentiell abwechselndaktiv.

Die Grenze überschreiten, sich bewusst seindass ${ }^{72}$ das volle Dreidimensionale und das leere Dreidimensionale vereinigt und trennt.

Die Grenze ist der wahre Protagonist des Raumes, so wie die Gegenwart (eine andere Grenze) der wahre Protagonist der Zeit ist.

Gibt es irgend einen Raum, der nicht in Verbindung mit den unzählbaren Räumen steht (wie Novalis sagt) eine räumliche Einheit oder vielleicht handelt es sich um eine grosse Einheit?

Ist vielleicht das, was isoliert, auch Raum mit einer anderen Zeit?

70 Esta cita la traduce Heidegger más abajo en su manuscrito.

71 Esta cita la traduce Heidegger más abajo en su manuscrito.

72 «seindass» aparece escrito así en el manuscrito de Heidegger. 
Manuscrito 2: Selección más Amplia de RefleXiones de Chillida, Que el artista PUDO HABER MANDADO A HEIDEGGER ${ }^{73}$

p. 51: Me interesa el proceso que siguen las cosas todas para pasar de un estado a otro. Crecimiento, evolución desarrollo etc... En general todos los procesos en los cuales uno de los actores es el tiempo. Los resultados parciales no me interesan en sí, sino en función de las relaciones entre ellos.

¿Qué se oculta tras lo que pudiéramos llamar repetición de elementos que sin ser idénticos, dada su proximidad y por desarrollarse entre límites precisos y cercanos, llegan a parecerlo?

p. 52: Es bastante sencillo, todo se reduce a aprender a preguntar.

En el extremo de lo agudo, el silencio. Atravesar el espacio silenciosamente. Conseguir la vibración muda.

Más allá y detrás de los conocimientos hay un lenguaje.

Más vale ciento volando que pájaro en mano.

p. 55: Se ve bien teniendo el ojo lleno de lo que se mira.

Hay una oculta comunicación entre todo lo que es próximo.

Ser espuma - sueño blanco de la ola. Fin de la respiración del mar.

El perfil de la rama movida por el viento.

Cada obra un paso entre lo conocido y lo ignorado.

Querer, osar, mirar, ver

En arte todo se puede aprender. Y nada, o casi nada, se puede enseñar.

p. 56: Cubierto de caminos y de piedras

recostado en la noche tan despacio

que el sonido se oye cuando llama.

Tengo las manos de ayer

me faltan las de mañana

la obra es para mí contestación y pregunta

La verdadera importancia de la razón reside en el poder que tiene de hacernos comprender sus propias limitaciones.

pp. 56,59

Las obras son ecos que conservan en el tiempo para el oído hermano la voz sorda en la luz.

73 Las páginas corresponden al libro: CHILlida, E. Schriften, op. cit. 
El presente como el pasado recuerdos del futuro.

$$
\begin{aligned}
& \text { La hierba y el cielo dicen, } \\
& \text { yo no sé decir. } \\
& \text { La mar y el aroma dicen, } \\
& \text { yo no sé decir. } \\
& \text { también yo digo, } \\
& \text { yo no sé decir. }
\end{aligned}
$$

p. 60: Quiero que mis obras sean quietas y calladas. Única manera de salir en parte de la influencia del tiempo.

p. 63: El pintor y el escultor están muy lejos entre sí. Una tercera dimensión que todo lo cambia los separa.

El punto de vista del escultor estará siempre a $90^{\circ}$ del punto de vista del pintor. El escultor encuentra los perfiles mirando siempre en profundidad.

pp. 64, 67: ¿Existen límites para el espíritu?

Gracias al espacio existen límites en el mundo físico y yo puedo ser escultor. Nada sería posible sin ese rumor de límites, y el espacio que los permite.

¿Qué clase de espacio permite los límites en el mundo espiritual?

p. 67: Todo es redondo alrededor de lo que gira siendo indiferente la forma de lo que gira. A la escultura se tiene acceso desde ese campo «redondo al rededor». No hay otra posibilidad.

La escultura debe siempre dar la cara y estar atenta a todo lo que alrededor de ella se mueve y la hace viva.

pp. 67-68: Hay un problema común en la mayor parte de mi obra, es éste el «espacio interior» consecuencia, y al mismo tiempo origen de los volúmenes positivos exteriores. Para definir estos espacios interiores, es necesario envolverlos, haciéndolos por lo tanto inaccesibles para el espectador situado al exterior. Los espacios interiores han sido siempre problema y preocupación de los arquitectos, suelen ser espacios de tres dimensiones definidos por superficies de dos. Yo aspiro a definir lo tridimensional (hueco) por medio de lo tridimensional (pleno), estableciendo al mismo tiempo una especie de correlación y diálogo entre ellos. Gracias a estas correlaciones los volúmenes exteriores, a los que tenemos fácil acceso, serán nuestro guía seguro para llegar a conocer, al menos en su espíritu, espacios ocultos.

pp. 71-72: Existen una serie de leyes en mis obras. Hablo del conjunto de la obra, que son fundamentales, que están en el origen de mi libertad trabajando, que están antes y por encima de las formas. El diálogo entre las formas, sean cuales fueren éstas, es mucho más importante que ellas mismas. A veces las obras no pueden ser, al menos para mí, y me veo obligado a abandonarlas, y es 
que no existe la posibilidad, o no he sido capaz de encontrarla, de correlacionar según estas leyes que son muy precisas, todo el universo, pequeño y primario, pero universo, que es cada obra.

p. 75: ¿Cómo es posible que nuestras vidas formadas por sucesivos presentes que no tienen dimensión dure unas veces 20, 40 u 80 años?

pp. 75-76: ¿Que clase de tiempo conduce a esa duración? Sin duda otro del que hablaba más arriba, y que por ser suma de de presentes sin dimensión tampoco puede tenerla.

p. 80: La unidad se busca no se posee.

pp. 88, 91: Dudar de la experiencia o carecer de ella. Eso es ser joven. Esta segunda forma es la más frecuente.

p. 91: El pasado y el futuro son dos muletas que el hombre se ha fabricado, para no pensar en el «pie sin dimensión» (presente)

Me mido a diario, para ver si he crecido, no para conocer mi estatura. Un hombre son medidas de todo orden en el tiempo.

La semejanza existe en la geometría, no en el arte. (p. 48: El punto en geometría no tiene medida, en arte sí.) El hecho de que el punto no tenga dimensión (p. 92) hace posible la semejanza y la geometría toda. ¿No será la no dimensión del presente lo que hace posible la vida?

p. 92: Sólo una de las tres dimensiones es activa (la que viene a mí desde lo lejano a través de lo próximo), pero las tres deben de serlo en potencia, alternando su actividad.

El presente ¿actividad (lugar activo) sin dimensión?

Pasar de un lado al otro del límite, tener conciencia de que une y separa lo tridimensional pleno de lo tridimensional hueco.

p. 95: El límite es el verdadero protagonista del espacio, como el presente (otro limite) es el verdadero protagonista del tiempo.

Lo que es solo de uno, es casi de nadie.

Los espacios con los que yo trabajo o son virtuales o son inaccesibles.

Una habitación con la puerta cerrada, es otra habitación, que la misma, con la puerta abierta.

pp. 95-96: ¿Es cualquier espacio que no comunica con los (espacios innombrables, como dice Novalis) una unidad espacial o se trata de parte de esa gran unidad.

p. 96: ¿Hay posibilidad de colocar un espacio fuera de ella? ¿No será lo que aísla también espacio con otro tempo? 
El deseo de experimentar, de conocer, me hace con frecuencia llevar en mi obra una marcha discontinua; que a lo mejor se debe a que me interesa más la experimentación que la experiencia, también prefiero el conocer al conocimiento.

También dentro de lo conocido se halla lo desconocido.

p. 99: Nunca se conoce bastante, de allí que también en lo conocido se halle lo desconocido y su llamada.

p. 111: Yo no represento, yo pregunto.

p. 124: ¿No será, justamente la densidad en todo su esplendor, necesaria para tratar del vacío.

p. 128: ¿No es la materia también espacio un espacio más lento?

$\begin{array}{clcl}\text { Espacio positivo - espacio negativo } \\ \text { “ } & \text { lento } & \text { " } & \text { rápido } \\ \text { “ } & \text { limitado } & \text { inmenso } \\ \text { “ } & \text { encadenado “ } & \text { libre } \\ \text { “ } & \text { diverso } & \text { “ } & \text { uno } \\ \text { “ } & \text { pesado } & \text { “ } & \text { liviano } \\ \text { “ } & \text { ahora } & \text { “ } & \text { siempre } \\ \text { “ } & \text { convexo } & \text { “ } & \text { cóncavo }\end{array}$

Desde el espacio con su hermano el tiempo bajo la gravedad insistente

En el espacio desde la gravedad insistente te saludo con admiración

p. 131: $\quad$ Saludo a J. S. Bach.

Moderno como las olas antiguo como la mar siempre nunca diferente pero nunca siempre igual. 
Manuscrito 3: apuntes de Heidegger sobre Chillida ${ }^{74}$

A continuación se reproduce en facsímil la página con apuntes de Heidegger sobre Chillida, que se han citado en el último capítulo de este artículo.

$$
\begin{aligned}
& \text { Zuivide ninf. tán. }
\end{aligned}
$$

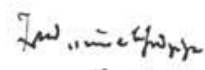

$$
\begin{aligned}
& \operatorname{tim} \text { Raimfigaim }
\end{aligned}
$$

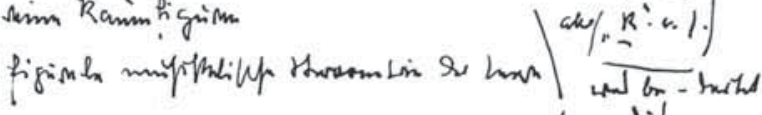

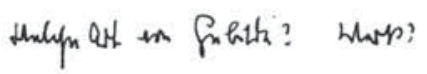

$$
\begin{aligned}
& \text { sil. }
\end{aligned}
$$

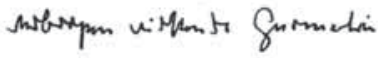

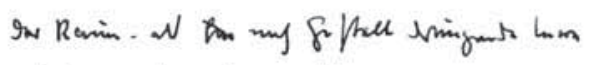

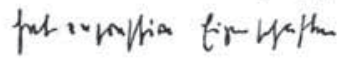

$$
\begin{aligned}
& \text { CRamin, teri, Firume }
\end{aligned}
$$

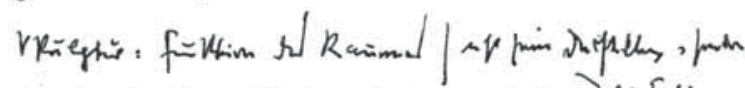

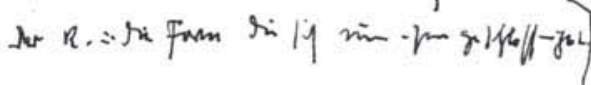

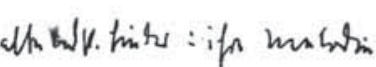

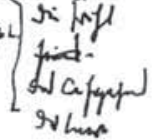

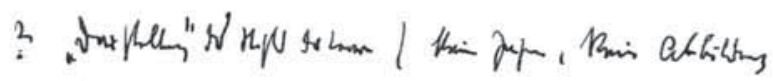

$$
\begin{aligned}
& \text { fuith? }
\end{aligned}
$$

Universidad de Antioquia (Medellín)

Ana María Rabe

ana.rabe@udea.edu.co

[Artículo aprobado para su publicación en diciembre de 2016]

${ }^{74}$ El manuscrito original se encuentra en el archivo del Deutsches Literaturarchiv Marbach. Con el amable permiso de Arnulf Heidegger reproducimos aquí en facsímil la primera página de los apuntes. Los apuntes completos, que Heidegger escribió en tres hojas de papel siendo la primera la más extensa, se publicarán próximamente junto con la correspondiente transcripción en un libro editado por mí. 
